\title{
Review Article \\ The Role of Chronic Inflammation in Obesity-Associated Cancers
}

\author{
Maria E. Ramos-Nino \\ Department of Pathology and Department of Medical Laboratory Sciences, University of Vermont, Burlington, VT, USA \\ Correspondence should be addressed to Maria E. Ramos-Nino; maria.ramos@med.uvm.edu
}

Received 17 April 2013; Accepted 12 May 2013

Academic Editors: P. Balaram, I. Faraoni, L. Hunakova, P. Karakitsos, and B. Luber

Copyright (C) 2013 Maria E. Ramos-Nino. This is an open access article distributed under the Creative Commons Attribution License, which permits unrestricted use, distribution, and reproduction in any medium, provided the original work is properly cited.

There is a strong relationship between metabolism and immunity, which can become deleterious under conditions of metabolic stress. Obesity, considered a chronic inflammatory disease, is one example of this link. Chronic inflammation is increasingly being recognized as an etiology in several cancers, particularly those of epithelial origin, and therefore a potential link between obesity and cancer. In this review, the connection between the different factors that can lead to the chronic inflammatory state in the obese individual, as well as their effect in tumorigenesis, is addressed. Furthermore, the association between obesity, inflammation, and esophageal, liver, colon, postmenopausal breast, and endometrial cancers is discussed.

\section{Introduction}

Cancer development is complex and involves different phases commonly referred to as initiation, promotion, and progression [1]. It is believed that during the initiation phase, genetic mutations accumulate that lead to irreversible cellular changes. Some of the most significant changes during this phase include activation of protooncogenes (e.g., ras, $b c l 2$, $m y c, a b l$ ) and inactivation of tumor suppressor genes (e.g., $p 53, R b)$ [1]. These genome-level events give a selective growth or survival advantage to the cell, which confer on cancer cells their intrinsic properties, including self-sufficient proliferation, insensitivity to antiproliferative signals, evasion of apoptosis, limitless replicative potential, sustained angiogenesis, invasion, and metastasis [2]. Tumor development is promoted by the clonal expansion of these changed cells, and it is followed by the progression phase, which involves tumor growth and metastasis [3].

Determining what causes a particular cancer is a complex task. Many things are known to increase the risk of cancer, including environmental pollutants [4-6], certain infections $[7,8]$, certain metabolic disorders $[9,10]$, and so forth. For example, skin cancer has been linked to radiation therapy; viral infections such as the human papilloma virus; exposure to UV radiation; aging; skin color; diet; smoking (reviewed in [11]).
Cancer cell initiation, promotion, and progression are also intimately linked to their microenvironment. The environment of the cells can directly affect their genetic make-up or, combined with genetic predisposition, help in the cancer development. The tumor infiltrate, composed of angiogenic vascular cells, lymphatic endothelial cells, cancer-associated fibroblastic cells, and immune cells, have been shown to contribute actively to tumorigenesis [12].

The contribution of immune cells in tumorigenesis was first addressed by Virchow in the middle of the 19th century [13]. His conclusions were based on the fact that tumors developed in the setting of chronic inflammation and that inflammatory cells were present in tumor biopsy specimens [14]. Today, chronic inflammation is increasingly being recognized as an etiology in several cancers $[13,15]$ (see Table 1), and most of the resulting tumors are of epithelial origin (carcinomas) [1]. Recent epidemiological data indicate that over $25 \%$ of all cancers are related to chronic inflammation [16] and it is estimated that $15 \%$ of cancer deaths are inflammation associated [17]. Some of the evidence to support this belief is the fact that some inflammatory diseases have been associated with increased risk of cancer development. For example, there is an estimate that about $15 \%$ of all malignancies worldwide are due to infections [17], and one of the mechanisms by which infectious agents may 
TABLE 1: Examples of inflammation-associated cancers.

\begin{tabular}{lcc}
\hline Inflammatory source & Cancer & Reference \\
\hline Environmental & Mouth, lung & Mesothelioma \\
Tobacco & Liver & \\
Asbestos & {$[26-28]$} \\
Alcohol & Colorectal, bladder \\
Infectious agent & Hodgkin disease \\
Schistosoma & Stomach \\
Epstein-Barr virus & Liver \\
Helicobacter pylori & {$[30]$} \\
Hepatitis B and C & Papilloma thyroid cancer \\
Physiological/metabolic conditions & Esophageal \\
Hashimoto thyroiditis & Prostate \\
Gastroesophageal reflux disease & {$[32]$} \\
Chronic prostatitis & Breast, liver, prostate, colon, esophageal \\
Obesity & {$[33]$} \\
\hline
\end{tabular}

induce carcinogenesis is the production of chronic inflammation [17]. Moreover, chronic overexpression of inflammatory mediators in the cell microenvironment can lead to increased tumor initiation, promotion, and progression $[18,19]$. For example, cyclooxygenase enzymes are required for the conversion of arachidonic acid to prostaglandins. COX-2 mediates the inflammatory effects of COX activity and is induced by a wide spectrum of growth factors and proinflammatory cytokines. COX-2 is overexpressed in numerous premalignant and malignant lesions, including colorectal cancer [20]. It has also been shown that inhibition of inflammatory mediators with anti-inflammatory drugs decreases cancer incidence and progression in patients with cancer [21-25].

The origin of the inflammatory tumor microenvironment is not currently clear. Two pathways have been postulated: (a) an intrinsic pathway where the source is the genetic alterations within the cancer cells and (b) an extrinsic pathway where the source could be a chronic infection, an autoimmune disease, chronic exposure to an irritant [37], or any other chronic comorbidity associated with an inflammatory process.

Metabolism and immunity are linked in many ways. They share many bioactive molecules that have both metabolic and immune functions, like bioactive lipids, cytokines, and others. The link between metabolism and immunity, which during homeostasis is beneficial to an individual's health, can become deleterious under conditions of metabolic stress, as exemplified by the obesity-linked inflammatory diseases like diabetes, atherosclerosis [38], and cancer.

Obesity, an abnormal or excessive fat accumulation in adipose tissues, is considered a chronic inflammatory disease [38]. The prevalence of obesity has increased dramatically over the past 30 years due to genetic, metabolic, behavioral, and environmental factors [39]. Approximately 35\% of adults and $20 \%$ of children in the US are currently obese [40]. A great majority of obese individuals meet the criteria for the metabolic syndrome: (a) increased waist circumference, (b) insulin resistance, (c) hyperglycemia, (d) hypertension, and (e) hypertriglyceridemia [41]. Obesity in turn increases risk for a number of chronic diseases including type 2 diabetes, cardiovascular disease, fatty liver disease, and some forms of cancer [39]. An estimated $15 \%-30 \%$ of cancer deaths in the US population are attributed to excess weight [40]. Evidence has accumulated that links obesity to endometrial cancer, postmenopausal breast cancer, colon cancer, renal cell carcinoma of the kidney, liver, gallbladder, esophageal, and pancreatic cancer, with some evidence for cervical, ovarian, prostate (prognosis), and stomach cancer [40]. Recent evidence has strengthened the proposed relationship between obesity-related insulin resistance and/or diabetes mellitus and cancer. Although the precise mechanisms and pathways are uncertain, hyperinsulinemia and possibly sustained hyperglycemia are important regulators of the development of cancer [10], but there is more to this association than meets the eye. The mechanisms by which inflammation is triggered in obesity/metabolic syndrome and how that can modify the tumor microenvironment are questions that have no clear answers. This review focuses on the inflammatory process and its impact in the tumor microenvironment as potential mechanisms underlying the association between obesity/metabolic syndrome and cancer development.

\section{Chronic Inflammation and Obesity}

Acute inflammation, a physiological process generated by the body in response to injury, infection, or irritation, is vital to healing; however, when this process becomes chronic it may contribute to a variety of diseases, including cancer.

In response to injury, infection, or irritation, the body initiates a network of chemical signals to heal the affected tissue. The inflammatory process involves activation and directed migration of leukocytes (neutrophils, monocytes, and eosinophils) from the vasculature to the site of injury. During this stage (a) adhesion molecules (L-, P-, and Eselectin) are activated that facilitate the rolling along the vascular endothelium; (b) integrins in leukocytes are activated and upregulated facilitating the immobilization of 
neutrophils on the surface of the vascular endothelium by tight adhesions; and (c) transmigration through the endothelium to sites of injury is facilitated by extracellular proteases, such as metalloproteinases (MMPs) [15]. The migration of leukocytes to the site of injury is orchestrated by a family of chemotactic cytokines, named chemokines. Neutrophils (or eosinophils) are the first to be recruited to the site of injury, followed by monocytes, which differentiate into macrophages. Once activated, macrophages are the main source of growth factors and cytokines which affect the local microenvironment. Mast cells also contribute to inflammatory mediators, such as histamine, cytokines, and proteases, as well as lipid mediators [15]. Many of the same molecular mediators are generated in both acute and chronic inflammations [1].

Obesity is associated with a low-grade chronic inflammation, characterized by increased circulating fatty acids, and chemoattraction of immune cells that contribute to the inflammatory condition [42]. Although the features of chronic inflammation in obese adipose tissue are clearly defined, the signals and mechanisms that trigger chronic inflammation are not well understood.

\section{Adipose Tissue}

Adipose tissue cells are embedded in a connective tissue matrix and contain a vast variety of cell types including preadipocytes, adipocytes, immune cells, and endothelial cells [43]. There are two types of adipose tissue: the brown adipose tissue (BAT) and the white adipose tissue (WAT). In humans, BAT is mainly an infancy-associated fat that specializes in generating heat. In adults, it has been located around the neck and large blood vessels of the thorax [43]. WAT, on the other hand, is the main source of energy reserves and the most common adipose tissue in adults. WAT constitutes the major source of fatty acids in the body, used as energy substrate for the generation of adenosine triphosphate (ATP) through oxidative phosphorylation [44]. WAT seems to have few key functions including the control of the metabolism through energy homeostasis, adipocyte differentiation, and insulin sensitivity $[45,46]$. In healthy, nonoverweight humans, white adipose tissue composes as much as $20 \%$ of the body weight in men and $25 \%$ of the body weight in women. Adipose tissue can be classified as subcutaneous and as visceral adipose tissue. The first is not related to many of the classic obesity-related pathologies, such as heart disease, cancer, and stroke, and some evidence even suggests that it might be protective around internal organs [47]. The visceral adipose tissue, on the other hand, is more predictive of obesity-associated comorbidity and mortality [42]. The adipocyte secretome and receptors are expressed differently in different adipose tissues.

\section{The Adipocyte}

The WAT's adipocyte or fat cell main function is lipid storage. In order to accommodate the lipids, adipocytes, which vary in size $(20-200 \mu \mathrm{m}$ in diameter), are capable of changing their diameter 20 -fold and their volume by severalthousand-fold [48]. More recently, adipocytes have recently been implicated in the modulation of a range of physiological responses, including lipid metabolism, glucose homeostasis, inflammation, angiogenesis, hemostasis, and blood pressure.

4.1. Adipogenesis. Adipocyte precursor cells emerge from mesenchymal stem cells. The pluripotent MSCs receive extracellular signals that lead to the determination of the preadipocyte linage. Adipogenic differentiation is characterized by arrested growth of proliferating preadipocyte and the increase expression of key adipocyte markers such as fatty acid-binding proteins, lipoprotein lipase, CCAAT/enhancer binding protein alpha $(\mathrm{C} / \mathrm{EBP} \alpha)$, and peroxisome proliferator-activated receptor gamma (PPAR $\gamma$ ) [49]. The later phase of adipogenesis is referred to as terminal differentiation.

It has long been proposed that new adipocytes arise solely from resident preadipocytes progenitors, but accumulating evidence points toward a contribution from outside sources, in particular the bone marrow [50,51].

4.2. Fat Storage and Release. The adipocyte stores triacylglicerides (TAGs). Approximately $90 \%$ of the adipocyte is a lipid droplet, and the remaining $10 \%$ consist of cytoplasm, mitochondria, nucleus, and other organelles (Figure 1). The steps for lipid storage and release depend on several critical molecules. The adipocyte releases lipoprotein lipase (LPL) to the environment to break down triglyceride molecules presented by two lipid transport molecules, the chylomicrons and the very low density lipoprotein (VLDL) into glycerol and free fatty acids. The free fatty acids enter the cell and are reformed into TAGs. Lipid release from the adipocyte was believed to be triggered via hormonal activation of hormonesensitive lipase (HSL). However, recent studies on HSLnull mice have challenged this concept [52]. Although HSLmediated lipolysis is a significant contributor to free fatty acid liberation from the adipocyte, other TAG lipases have been identified including desnutrin/ATGL [52]. Lipolysis is under tight hormonal regulation, with insulin as an inhibitor and catecholamines, as well as potentially other factors, as stimulants of lipolysis in the adipocyte [52].

Other molecules of importance during fat uptake and release by the adipocyte are the lipid droplet-associated protein Perilipin, which restricts access of TAG lipases during the unstimulated state [53]; the adipose fatty acid binding protein (aFABP), a carrier protein for free fatty acids, eicosanoids, and retinoids, thought to facilitate the transfer of fatty acids between extra- and intracellular membranes $[54,55]$ and lipophilic molecules from outer cell membrane to intracellular receptors such as PPAR [56]; aquaporin 7 which exports the glycerol molecule released from TAGs [57]; and CD36 which facilitates free fatty acid transport through the plasma membrane [58] (see Figure 2).

4.3. The WAT's Adipocyte Secretome and Receptors. The first signaling molecule found to originate from the adipocyte was Leptin in 1994 [59-64]. Since then, a vast array of signaling 


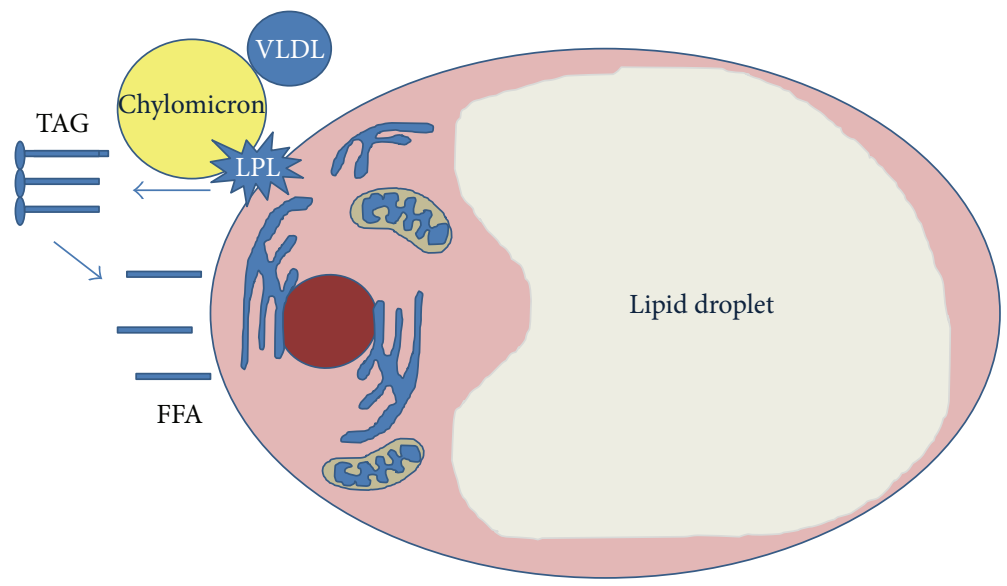

FIGURE 1: The WAT's adipocyte cell storage triglycerides (TAGs). Approximately $90 \%$ of the adipocyte is a lipid droplet. The steps for lipid storage. (a) The adipocyte releases lipoprotein lipase (LPL) to the environment to break down triglyceride molecules presented by the chylomicrons and the very low density lipoprotein (VLDL) into glycerol and free fatty acids. The free fatty acids enter the cell and are reformed into TAGs.

molecules has been added to that list (Figure 3). Similarly, the adipocyte expresses plasma membrane receptors that include the hormone-cytokine receptor, thyroid-stimulating hormone, glucagon, IL-6, TNF $\alpha$, gastrin/cholecystokinin$\mathrm{B}$, neuropeptide $\mathrm{Y}-\mathrm{Y} 1$, atrial natriuretic peptide, epidermal growth factor, platelet-derived growth factor, fibroblast growth factor, gastrin inhibitory peptide, glucagon like peptide-1, angiotensin II, leptin (OB-R), growth hormone, prostaglandin, adenosine, lipoprotein lipase and insulin; the lipoprotein receptor, very low density lipoprotein, low-density lipoprotein, and high-density lipoprotein; the catecholamine-nervous system receptors, $\beta 1, \beta 2, \beta 3, \alpha 1, \alpha 2$; and the nuclear receptors, peroxisome proliferator-activated receptor gamma (PPAR $\gamma$ ), retinoic acid receptors (RAR and RXR), estrogen, androgen, vitamin $\mathrm{D}$, thyroid hormone, progesterone, and glucocorticoids (summarized in [48]).

\section{Obesity}

Obesity, a medical condition in which people's body mass index (BMI) exceeds $30 \mathrm{~kg} / \mathrm{m}^{2}$, is the sixth most important risk factor contributing to the overall burden of disease worldwide [65]. Obesity is associated with a chronic state of inflammation, but the causes and mechanisms involved in obesity-induced inflammation are not fully understood. Accumulating evidence indicates that obesityinduced inflammation can be in part attributed to increased fatty acids; inflammatory cytokine production of the expanding adipose tissue; the influx of immune cells that add to the production of inflammatory mediators [42].

Under normal conditions, adipocytes store lipids and regulate metabolic homeostasis. Under these conditions, resident tissue macrophages present a predominant polarization of M2 type, release mainly anti-inflammatory cytokines [66, 67] like IL-10, IL-1R $\alpha$, and the enzyme arginase, involved in the inhibition of nitric oxide synthase (iNOS) $[66,68]$. Normal WAT potentially contributes to this anti-inflammatory environment through peroxisome proliferator-activated receptors (PPARs) and liver X receptor
(LXR) cell signaling $[69,70]$. In obesity, WAT becomes an inflammatory source and the change in the cytokine profile induces the resident macrophages to a more activated M1 type (CD11 c+) [66, 68, 71, 72]. M1 macrophages release iNOS and proinflammatory cytokines [72]. However, macrophage subsets in WAT show no strict M1 or M2 subtypes [66, 73]. Beside the resident macrophages, an increased influx of macrophages occurs in WAT during obesity, which exacerbates the inflammatory state $[74,75]$. The obesity-induced inflammatory cytokines seem to be responsible for the activation of adhesion molecules in endothelial cells and the recruitment of monocytes and macrophages [76]. In addition to macrophages, other immune cells localized to adipose tissue in obesity include neutrophils, mast cells, natural killer $\mathrm{T}$ cells, and lymphocytes. Whether the infiltration of these other immune cells is causal to, or result of, an increased inflammatory environment seen in obesity is not known [77]. Adipocytes from visceral body depots show a more inflammatory profile than those from subcutaneous fat [78]. As the demand for fat storage increases, obesity brings about hyperplasia as well as hypertrophy of the adipose tissue $[73,79,80]$. Adipocyte hypertrophy is induced by two factors: increased fat storage in differentiated adipocytes and increased expression of proinflammatory mediators [80, 81]. As the process from lean to the obese state occurs, radical changes happen in the adipocyte microenvironment, as well as the intracellular adipocyte state, including hypoxia, endoplasmic reticulum stress, and mitochondrial stress that result in insulin resistance, changes in the adipocyte secretome, free fatty acid dysregulation, and chronic inflammation.

5.1. Adipocyte Microenvironment. As the adipose tissue expands, a partial break down of the extracellular matrix (ECM) is required in order to prevent the extracellular matrix from restraining the expanding adipocytes. Failure to do so could result in problems such as ectopic lipid deposition and lipotoxic effects in organs like the liver, muscle, and pancreas [82]. Key extracellular components during these changes are, among others, those associated with fibronectin 


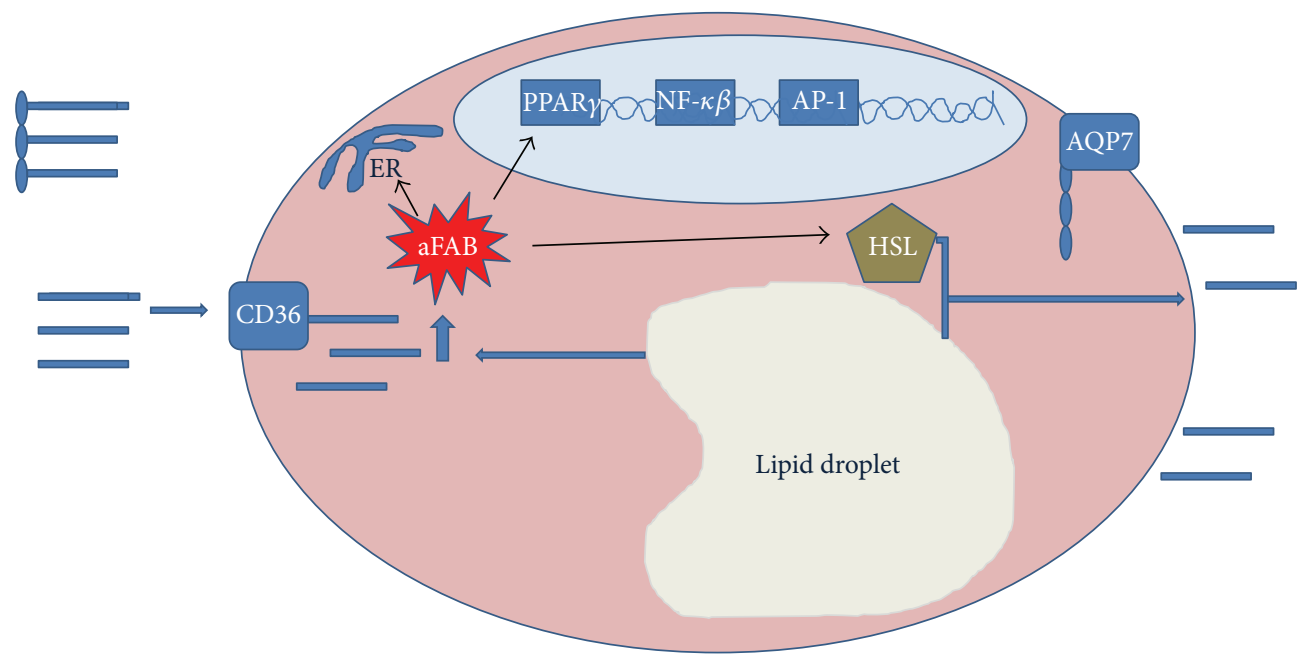

FIGURE 2: Important molecules during fat release by the WAT's adipocyte. Lipid release from the adipocyte is in part triggered via (a) hormonal activation of hormone-sensitive lipase (HSL); (b) the adipose fatty acid binding protein (aFABP), a carrier protein for free fatty acids, eicosanoids, and retinoids, thought to facilitate the transfer of fatty acids between extra- and intracellular membranes, and lipophilic molecules from outer cell membrane to intracellular receptors such as PPAR; (c) aquaporin 7 which exports the glycerol molecule released from TAGs; and (d) CD36 which facilitates free fatty acid transport through the plasma membrane.

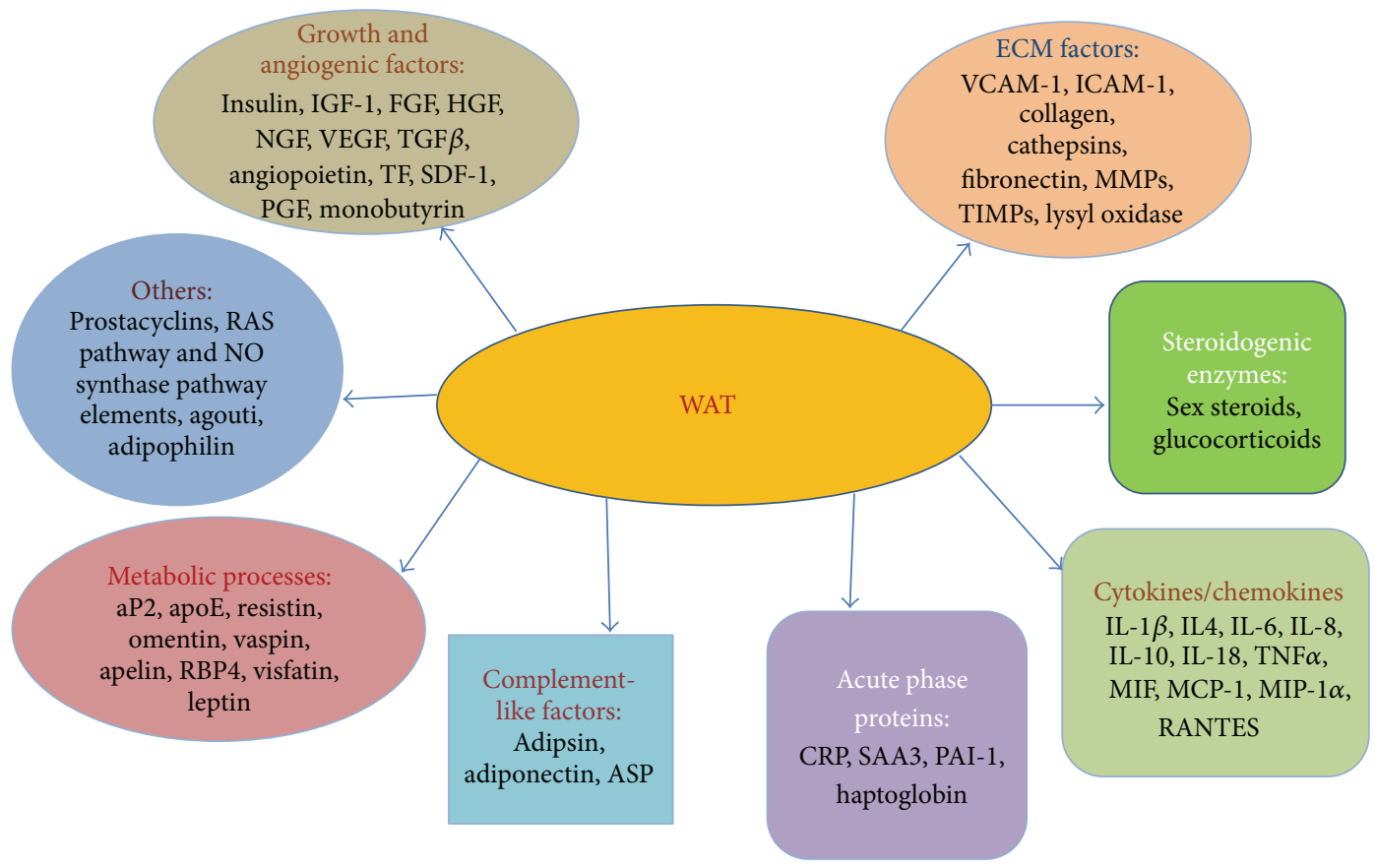

FIGURE 3: Signals emanating from the white adipose tissue. ASP: acylation-stimulating protein; aP2: activating protein 2; apoE: apolipoprotein E; RBP4: retinol binding protein 4; RAS: rennin-angiotensin system; NO synthase: nitric oxide synthase; IGF-1: insulin-like growth factor 1; FGF: fibroblast growth factor; HGF: hepatocyte growth factor; NGF: nerve growth factor; VEGF: vascular endothelial growth factor; TGF $\beta$ : transforming growth factor beta; TF: tissue factor; SDF-1: stromal derived factor; PGF: placental growth factor; VCAM-1: vascular cell adhesion molecule 1; ICAM-1: intracellular adhesion molecule 1; MMPs: matrix metalloproteinase proteins; TIMPs: tissue inhibitor of metalloproteinase; IL: interleukin; TNF $\alpha$ : tumor necrosis factor alpha; MIF: macrophage migrating inhibitor factor; MCP-1: monocyte chemotactic protein-1; MIP-1 $\alpha$ : macrophage inflammatory protein 1; RANTES: Regulated on Activation, Normal T cell Expressed and Secreted; CRP: C-reactive protein; SAA3: serum amyloid A3; PAI-1: plasminogen activator-1. 
in the ECM. Cathepsin S, an adipokine and cysteine protease involved in the degradation of fibronectin, is upregulated in the obese state and is involved in the differentiation of human preadipocytes [83]. Another upregulated protease, Cathepsin $\mathrm{K}$, can degrade collagens and is required for the induction of lipid storage program during 3T3-L1 differentiation [84]. Some matrix metalloproteases (MMPs) and their control regulatory protein, the tissue inhibitory of matrix metalloproteinases (TIMPs), are also secreted by the adipocyte and dysregulated in the obese state, although the role of these proteases and protease- inhibitors in obesity is not clear [43].

5.2. Hypoxia. In order for growing fat mass to sustain its growth, ongoing neovascularization is also required. New endothelium can be made of endothelial cells already present in the adipocyte microenvironment or by the maturation of new endothelial cells from circulating endothelial progenitors $[85,86]$. Strong evidence on the effect of angiogenesis on adipose tissue expansion comes from studies where the use of angiogenesis inhibitors triggered a reduction in fat mass [87-89]. The adipocyte secretes a vast array of factors that modulate angiogenesis (see Figure 3). Nevertheless, a rapidly expanding fat mass still experiences hypoxia [90-92]. During hypoxia a large amount of proangiogenic molecules are secreted by the adipocyte $[93,94]$ and the macrophages in its microenvironment $[91,95]$. Macrophages have a very active role in angiogenesis under normoxic condition but become even more active during hypoxia. Recently it has been observed that obesity induces a phenotypic switch from the M2 phenotype involved in tissue remodeling, angiogenesis, and a type 2 inflammatory response to the $\mathrm{M} 1$, a phenotype involved in the killing of intracellular parasites and type 1 inflammatory response, thereby decreasing the angiogenic potential of the macrophages in adipose tissue [96].

The role of hypoxia in chronic inflammation in adipose tissue was first proposed by Trayhurn and Wood [97]. Recent studies have provided consistent evidence that adipose tissue hypoxia exists and that it contributes to initiation of chronic inflammation and inhibition of adiponectin expression in the white adipose tissue [90-92, 98-100].

\subsection{Reactive Oxygen Species (ROS). Oxidative stress is caused} by an imbalance between increased production of reactive oxygen species (ROS) and reduced antioxidant activity, leading to oxidative damage to cells [101]. It is well known that oxidative stress is involved in the pathology of several diseases, including cancer, diabetes mellitus, hypertension, and cardiovascular diseases [101, 102]. Several studies have suggested that obesity is associated with increased oxidative stress [103-107] and inversely correlated to antioxidant capacity $[108,109]$. Some of the potential mechanisms of obesity-associated oxidative stress are, among others, the adipose tissue itself. An inflammatory process, especially in visceral obesity, is observed as WAT mass increases. This inflammatory process is activated in the WAT itself, liver, and immune cells $[71,74,110,111]$. This response determines an increase in circulating levels of proinflammatory cytokines, hormone-like molecules, and other inflammatory markers [71]. These adipokines in turn are stimulators for the production of reactive oxygen species and nitrogen species by macrophages and monocytes [112, 113]. Adipose tissue also produces angiotensin II, which stimulates nicotinamide adenine dinucleotide phosphate (NADPH oxidase) activity, one of the major sources for ROS production in adipocyte $[102,114]$. Also, free fatty acids can contribute to oxidative stress, as described in the next section. Several studies have demonstrated that obesity could also deplete antioxidant sources, decreasing the activity of enzymes such as superoxide dismutase (SOD), glutathione peroxidase (GPx), and catalase (CAT) [113].

5.4. Free Fatty Acids. WAT is a major source of nonesterified fatty acids, also called free fatty acids (FFAs), used as energy substrate for the generation of ATP after oxidative phosphorylation. Adipocytes of obese people have reduced insulin receptors and an increase in beta-3 adrenergic receptors, which contribute to the increase in lipolysis rate [113]. Hyperlipidemia leads to increased uptake of fatty acids by skeletal muscle, liver, heart, and pancreatic $\beta$-cells [115]. These nonadipose tissues are less capable of storing lipids than the adipocytes which increase the accumulation of toxic fatty acid metabolites that stimulate inflammation and inhibit insulin signaling [116]. Excessive fat accumulation can also cause cellular damage, as in nonalcoholic steatohepatitis [113]. The cellular damage leads to production of cytokines such as $\mathrm{TNF} \alpha$, which in turn generates ROS in the tissues, increasing the lipid peroxidation rate [117].

Mitochondrial and peroxisomal oxidation of fatty acids is capable of producing free radicals in cells, which could result in mitochondrial alterations. The mitochondrial function is key for the proper maintenance of energy homeostasis. Even small changes in the level of mitochondrial function have a dramatic effect on production and release of adipokines in the adipocytes, particularly adiponectin [118], an adipokine involved in anti-inflammatory, antioxidant, and other processes [71].

Lipids can also be anti-inflammatory. Ligands of the LXR and PPAR families of nuclear hormone receptors are oxysterols and fatty acids, respectively, and activation of these transcription factors inhibits inflammatory gene expression in adipocytes and macrophages, largely through suppression of $\mathrm{NF} \kappa \mathrm{B}[69,70,119,120]$.

An example of inflammatory fatty acids is arachidonic acid (n-6 fatty acid), a precursor of immune-active mediator known as eicosanoids (lipoxins, leukotrienes, and prostaglandins) (reviewed in [121]). On the other hand, n-3 fatty acids and some of its derivatives, including resolvins (generated from n-3 fatty acids docosahexaenoic acid (DHA) and eicosapentaenoic acid (EPA)), have potent anti-inflammatory and immunoregulatory actions. In the case of resolvins, they can prevent neutrophil entry to inflammation sites and cytokine production [122]. Some studies demonstrate an increase in resolving D1 and 17-hydroxyDHA, a marker of resolving synthesis, in adipose tissue of obese-diabetic mice fed with n-3 fatty acids [123]. Other n-3 fatty acid-derived lipid mediators like protectin D1 and other aspirin-triggered lipoxins are produced after acetylation of 
COX-2 by aspirin and help in the anti-inflammatory process by inhibition of neutrophils tissue infiltration and stimulation of macrophage phagocytosis of apoptotic neutrophils [124].

The role of lipids in inflammation depends on the location in the body, the composition of the microenvironment, and their coupling to target signaling pathways [38].

5.5. Endothelial Reticulum Stress (ER). The ER, an organelle in which proteins are synthesized, folded, and matured [125], is responsive to cellular nutrient and energy status [77]. Recent studies have suggested that ER stress and the unfolded protein response (UPR), a system that mitigates ER stress, are activated under obese conditions [38, 126-129]. Three major transducers of the UPR have been identified, including PKR-like ER kinase (PERK), part of the family of eIF2 $\alpha$ kinases whose activation results in expression of proapoptotic transcriptional factors CCAAT/enhancer binding protein $(\mathrm{C} / \mathrm{EBP})$, homologous protein $(\mathrm{CHOP})$, and growth arrest and DNA damage-inducible protein 34 (Gadd 34) [130, 131]; inositol-required enzyme 1 (IRE1), involved in splicing of X-box binding protein-1 (XBP-1) mRNA, and translation of the spliced form, which in turn regulates the expression of ER chaperons and proteins involved in ER-associated degradation [132]; and activating transcription factor 6 (ATF6), that translocates to the Golgi Apparatus in response to ER stress where it is cleaved. The $\mathrm{N}$-terminal fraction regulates ER chaperone expression [133]. These factors in turn activate three pathways: (a) suppression of protein translation, (b) induction of genes encoding ER molecular chaperons (BiP (GRP78), ORP150 (oxygen regulated protein 150), calnexin, calreticulin, and so forth) to facilitate protein folding, and (c) ER-associated degradation to reduce unfolded protein accumulation in the ER [134]. UPR failure induces apoptosis in cells [134]. Studies have demonstrated that FFAs have the potential to induce ER stress in adipocytes $[135,136]$ and the use of chemical chaperones, that alleviate ER stress, suppressed the inflammatory response and improved insulin resistance in adipose tissue [136].

ER stress and all three arms of the UPR are linked to major inflammatory and stress-signaling pathways, including the activation of JNK-AP-1 and IKB kinase nuclear factor $\mathrm{kB}$ (IKK- NF $\kappa \mathrm{B}$ ) and the production of ROS which are pathways that play a central role in obesity-induced inflammation [128, $137,138]$ and probably other pathways as well [77].

\section{Obesity, Chronic Inflammation, and Cancer}

Worldwide there are 1.1 billion overweight people with a BMI between $25 \mathrm{~kg} / \mathrm{m}^{2}$ and $30 \mathrm{~kg} / \mathrm{m}^{2}$ and 312 million with a BMI $>30 \mathrm{~kg} / \mathrm{m}^{2}$ [65]. The American Cancer Society calculates that currently new cancer cases are in the order of 1.5 million with 0.5 million cancer deaths per year, nearly 1 in 5 due to obesity [139]. A large number of epidemiological studies link obesity/metabolic syndrome/diabetes-associated diseases to an increased risk for the development of several types of cancer, particularly gastrointestinal, glandular, and reproductive tract cancers $[140,141]$. In addition, obesity can lead to poorer treatment outcomes, worsened prognosis, and mortality [142-146].

A comprehensive systematic review of the evidence by the World Cancer Research Fund (ECRF) and the American Institute for Cancer Research (AICR) concluded that obesity is an established risk factor for several cancers [141]. In a standardized meta-analysis of prospective observational studies by Renehan et al., 2008 (1966-2007: 221 datasets; 282, 137 incident cases; 20 cancer types), quantifying associations between a $5 \mathrm{~kg} / \mathrm{m}^{2}$ increase in BMI and risk of incident cancer, showed that, in men, the increase was associated with (a) oesophageal adenocarcinoma (RR 1.52, $P<0.0001)$; (b) thyroid (1.33, $P=0.02)$; (c) colon (1.24, $P<0.0001)$; and (d) renal $(1.24, P<0.0001)$ cancers. In women, the association was found for (a) endometrial (1.59, $P<0.0001)$; (b) gallbladder (1.59, $P=0.04)$; (c) oesophageal adenocarcinoma (1.51, $P<0.0001)$; and (d) renal $(1.34, P<0.0001)$ cancers. Weaker positive associations $(\mathrm{RR}<1.20)$ were found in men with rectal cancer and malignant melanoma and in women with postmenopausal breast, pancreatic, thyroid, and colon cancers. They also found an association for both sexes with leukemia, multiple myeloma, and non-Hodgkin lymphoma. The associations were generally similar in studies from North America, Europe, and Australia, as well as the Asia-Pacific region [147]. Studies with long-term followup of patients undergoing bariatric surgery for morbid obesity showed a reduction in cancer incidence in women associated with sustained weight loss supporting a causal association between obesity and cancer risk [148, 149].

One of the major challenges in the association of obesity and cancer has been linking the epidemiology with the biological basis. Biological mechanisms underlying the relationship between obesity and cancer are poorly understood. Of the most studied candidates for this association are the energy balance-associated factors (adipokines, growth factors, hormones, and their cell signaling pathways) [141], and other emerging candidates include obesity-associated hypoxia, genetic susceptibility, adipose stromal cells, and inflammatory processes [150].

\section{Energy Balance-Associated Factors}

Several energy balance-related factors are known to influence tumor progression and these have been implicated as contributors to the effects of obesity on cancer outcome. These factors include leptin, adiponectin, steroid hormones, insulin, insulin-like growth factor-1, and sirtuins [151, 152].

7.1. Leptin. A peptide hormone is encoded by the $o b$ gene, which is produced primarily by WAT, but it can also be secreted by cells of the placenta, ovaries, mammary epithelium, brown adipose tissue, skeletal muscles, the fundal glands of the stomach, bone marrow, pituitary, and the liver [153]. Leptin signals through the leptin receptor (LEPR), encoded by the $d b$ gene, and different variants are produced through alternative splicing of the gene. The long form of the receptor, LEPR-B, has a cytoplasmic domain that transduces the leptin-mediated signaling [154]. Leptin is 
involved in hypothalamic regulation of body weight and energy balance by promoting a sensation of satiety [40]. Genetic loss-of-function mutants for leptin or its receptor in mouse models (i.e., ob/ob or $\mathrm{db} / \mathrm{db}$ mice) develop systemic metabolic abnormalities that include obesity, diabetes, infertility, and immune defects [155]. In the obese state, leptin is overproduced and leptin resistance usually develops $[40,156]$. Increased concentrations of leptin in the obese are associated with greater amounts of adipose tissue [157, 158] that in turn affect immune function, cytokine production, angiogenesis, carcinogenesis, and other processes [159]. Leptin has been extensively studied as a potential mediator of obesity-associated cancer [160]. Leptin signaling plays an important role in tumor cell growth and survival that may be mediated through a set of responses of LEPRpositive tumor cells [154] including cancer stem cells [161]. It is activated by insulin, glucocorticoids, tumor necrosis factor-alpha (TNF $\alpha$ ), and estrogens [159] and induces cancer progression by activation of the JAK2/STAT3 [162], PI3K, and MAPK pathways [163-166] through LEPR-B. A number of studies indicate that LEPR are overexpressed in many tumor tissues and that there are leptin-responsive tumors including mammary carcinomas, pancreatic, esophageal, gastric, and colon tumors [167-170]. Leptin triggers cell proliferation, migration, and invasion in different cell types [154, 171], antiapoptotic and proangiogenic effects, alone or in synergy with vascular endothelial growth factor (VEGF) $[172,173]$, and is a proinflammatory agent [150], inducing $\mathrm{T}$ helper 1 cells and potentially contributing to the progression of autoimmune responses [174].

7.2. Adiponectin. A peptide hormone, secreted mostly from visceral adipose tissue, is involved in energy homeostasis, carbohydrates, and lipid metabolism $[175,176]$. This hormone is present in plasma as two epimers: low molecular weight (LMW) and high molecular weight (HMW) [177, 178]. The HMW forms of adiponectin predominate in the serum of healthy individuals and are normally decreased in obesity $[139,179,180]$. Furthermore, high levels of adiponectin have been associated with low body fat [181, 182]. Adiponectin improves fatty acid catabolism [183]; increases insulin sensitivity, possibly as a result of its role in lipid peroxidation, improvement of insulin signaling, inhibition of TNF $\alpha$, or/and inhibition of gluconeogenesis [184]; and exhibits antiinflammatory characteristics, possibly by suppressing the migration of anti-inflammatory mediators such as monocytes and macrophages [184]. Adiponectin may exert part of its anticancer effects by (1) decreasing insulin/insulinlike growth factor-1 (IGF-1) secretion, (2) modulating mTOR signaling by activating AMP-activated protein kinase (AMPK) and peroxisome proliferator-activated receptor $\operatorname{PPAR} \gamma$ metabolic pathways, leading to an increase in fatty acid oxidation, glucose uptake, and a decreased rate of gluconeogenesis, thus enhancing insulin sensitivity, and (3) exerting anti-inflammatory action via the inhibition of nuclear factor kappa-light-chain-enhancer of activated B cells (NF- $\kappa$ B) [185]. Activation of NF- $\kappa$ B is a potential mechanism through which inflammation may stimulate cancer development $[42,152]$. Several studies have suggested that higher levels of adiponectin are associated with higher levels of high density lipoproteins (HDL) and lower levels of low density lipoprotein (LDL), triglycerides (TGs), and total cholesterol [186]. Dyslipidemias, like low HDL, high LDL, and high TGs levels, are associated with some cancers including lung, non-Hodgkin lymphoma and have been suggested to be a marker for increased breast cancer risk, since they may reflect unfavorable hormonal profile with increased estrogen levels in obese women [187-190]. High serum levels of cholesterol and TGs raise the risk of prostate cancer and postmenopausal breast cancer [191, 192]. Furthermore, adiponectin plays a role in the secretion of estrogen [193] and estrogen plays a role in cancer development, as discussed later.

In population-based studies, it has been found that adiponectin levels are inversely associated with increased risk of cancer, including endometrial, breast (postmenopausal), colon, esophageal, prostate cancers, and pancreatic cancer in men [177, 194-200]. Most studies suggest that adiponectin may have protective effects against the development of cancer, and that the association is correlated with estrogen, IGF, obesity, and insulin resistance. Further investigations are needed to clarify these associations.

7.3. Steroid Hormones. Steroid hormones, including adrenal steroids, androgen, progesterone, and estrogen, are associated with energy balance and obesity-associated progression of several cancers [201]. Adipose tissue can produce estrogens in men, postmenopausal or ovarian-hormone-deficient women, via aromatase-catalyzed conversion of gonadal and adrenal androgens $[141,202]$. Obesity also increases the bioavailability of estradiol by reducing the production of sex hormonesbinding globulin (SHBG) $[139,202]$, raising the risk of postmenopausal breast, endometrial, and colon cancers [202]. In support of this, data from the Endogenous Hormones and Breast Cancer Collaborative Group (EHBCCG) [203], a pooled analysis of nine prospective studies and the European Prospective Investigation into Cancer and Nutrition (EPIC) study [204], demonstrate that postmenopausal breast cancer risk is increased among women with higher concentrations of circulating sex steroids and lower levels of SHBG. Adiposity has been inversely related to testosterone concentrations in men [205] but positively related in women [203]. However, the experimental evidence in women is conflicting [150]. Similar to breast cancer, epidemiological studies have shown that higher levels of estrone and estradiol are associated with increased endometrial cancer risk in postmenopausal women [202]. Androgenic and estrogenic steroids have also been identified as key risk factors in the etiology of colorectal cancer (CRC). In population studies, women taking hormone replacement therapy have been found to have a reduced colorectal cancer risk [206, 207]. Furthermore, genetic polymorphisms in both androgen and estrogen receptors are associated with altered CRC risk [208].

The role of estrogen in inflammation is complex. On one hand, studies have observed suppression of inflammation with increased estrogen in several animal models of chronic inflammatory diseases. On the other hand, there is evidence of proinflammatory effects in some chronic autoimmune 
diseases in humans [209]. The effects of estrogens are dependent on criteria such as (1) the immune stimulus (foreign antigens or auto antigens); (2) the cell types involved during different phases of the disease; (3) the target organ with its specific microenvironment; (4) the reproductive status of a woman; (5) the concentration of estrogens; (6) the variability in expression of estrogen receptor $\alpha$ and $\beta$ depending on the microenvironment and the cell type; and (7) intracellular metabolism of estrogens leading to important biologically active metabolites with quite different anti- and proinflammatory functions (reviewed in [209]). The concept that estrogens have anti-inflammatory, but also proinflammatory roles, depending on afore-mentioned criteria, makes it difficult to elaborate on its effect in obesity-associated cancers. It is known that estrogen represses IL-6, a proinflammatory and anti-inflammatory cytokine, through an ER-dependent mechanism, and that serum levels of IL-6 increase following menopause, in healthy women, and with age in both men and women [210, 211].

7.4. Insulin and Insulin-Growth Factor-1. Insulin is a peptide hormone produced by the beta cells of the pancreas and released in response to elevated blood glucose. In the obese state, blood glucose levels increase and trigger the pancreas to increase insulin production, resulting in hyperinsulinemia, hyperglycemia, and insulin resistance [212-214]. The development of insulin resistance is linked to chronic inflammation and the production of adiponectin and IGF-1 [215-217]. The insulin growth factor-1 system comprises three peptides, insulin, IGF-1, IGF-2 and each of its receptors (IR, IGF-1R, IGF-2R), as well as at least six IGF-binding proteins (IGFBPs). IGF-2 is a fetal growth factor [218] while IGF-1 stimulates fetal as well as postnatal growth [139]. IGF-1 is a peptide growth factor that shares approximately $50 \%$ sequence homology with insulin and is produced primarily by the liver following stimulation mainly by growth hormone, as well as hyperinsulinemia and hyperglycemia [40]. IGF-1 circulates bound to IGFBPs, and when free, binds to its IGF-1R, eliciting growth and survival signaling [219]. The growth promoting effects of IGF-1 include proliferation, differentiation, protein synthesis, modulation of cyclins and cyclin-dependent kinase inhibitors [220], proangiogenic action [221], and inhibition of apoptosis $[139,222]$. Similar to insulin, levels of IGF-1 correspond to energy status and are often elevated in obesity [145, 223], possibly via hyperglycemia-induced suppression of IGFBPs synthesis and/or growth hormone receptor expression and IGF-1 synthesis [219, 224]. However, the relationship between BMI and circulating IGF-1 and IGFBPs is complex and nonlinear [225]. Hyperinsulinemia increases the risk for colorectal, kidney, breast, endometrial, and pancreatic cancers [226-229]. The proliferative effects of insulin are believed to be an indirect effect through increasing levels of bioavailable IGF-1 [42, 230], and the role of IGF-1 as a risk factor for cancer has been well established [231-234].

The signaling processes downstream of IGF-1R activation are similar to those of insulin and involve two major signaling pathways, the mitogenic extracellular signalregulated kinase (ERK) and the metabolic and antiapoptotic phosphatidylinositol-3-kinase (PI3K) pathways, important to the modulation of transcription factors that control gene expression related to cancer development $[42,235]$. Activation of the insulin receptor (IR) and the IGF-1R stimulate PI3K, which in turn activates Akt, a regulator of the mammalian target of rampamycin (mTOR). mTOR activation results in protein synthesis, preparation of mitosis through S6k1 and 4E-BP-1, and cell growth, all processes that support tumor growth [236]. mTOR is inhibited by two tumor suppressors, phosphatase and tensin homolog (PTEN) and tuberous sclerosis (TSC) [237], and by increased AMPactivated kinase (AMPK) under low nutrient conditions and hypoxia [238]. PTEN is one of the most commonly mutated tumor suppressor genes in human cancer. The loss of this tumor suppressor results in an increased signaling of IGF-2 through IGF-1R and IR-A [239]. IGF-1 also mediates its effect through the MEK-ERK pathway. It is conceivable that in some cell types it might be necessary to activate multiple signaling pathways at once to avoid apoptosis, and that the signals activated depend on the specific cell type [222]. Estrogen is another factor that can activate the MEK-ERK pathway. Estrogen was demonstrated to induce the expression of IGF$1 \mathrm{R}$ as well as the insulin receptor substrates IRS- 1 and IRS- 2 in breast tumor cells. This leads to the activation of MAPK after IGF-1 stimulation [240].

7.5. Sirtuins. Lysine acetylation/deacetylation has been recognized as an important posttranslational modification, regulating numerous cellular processes. Sirtuins, NADdependent lysine-deacetylases, have recently been associated with the regulation of lifespan in lower organisms and their capacity to interfere with cell growth, proliferation, and survival in response to stress [241]. Their requirement for NAD suggests that these enzymes may represent an important molecular link between metabolism and several human disorders such as diabetes and cancer [241]. Sirtuins have been associated with regulation of aging, endocrine signaling, transcription, and metabolic changes associated with obesity [152]. In mammals, sirtuin 1 (SIRT1) promotes long-term survival of cells [242]. SIRT1 is a nicotinamide adenine dinucleotide-dependent deacetylase that acts on $\mathrm{Ku} 70$, which in turn sequesters the proapoptotic factor Bax from the mitochondria, thus inhibiting stress-induced apoptosis [242]. Sirtuins have been shown to regulate several obesity-associated metabolic changes including regulation of adiponectin secretion [243, 244], insulin secretion and sensitivity, plasma glucose levels $[245,246]$, regulation of oxygen consumption, and mitochondrial capacity $[247,248]$. Conflicting results exist as whether SIRT1 is a tumor suppressor gene or an oncogene [249]. SIRT1 is upregulated in several tumor types and can inhibit apoptosis and downregulate the expression of tumor suppressor genes to impact epithelial cancer cells [250]. Preclinical studies suggest that activation of SIRT1 could be a cancer prevention strategy [251]. In general, sirtuins play key roles in tumourigenesis, as some have tumor-suppressor functions and others influence tumors through their control of the metabolic state of the cell [252]. Cancers associated with Sirtuins are, among others, SIRT1 with acute myeloid leukemia, colon, bladder, prostate, ovarian and glioma cancers; SIRT2 with glioma; SIRT3 and 
SIRT4 with breast cancer; SIRT 5 with pancreatic and breast cancers; SIRT6 with colon and breast cancers, and SIRT7 with breast cancer [252].

Recently, the identification of several transcription factors, known to play a role in the immune system, as sirtuin substrates, has suggested that this family of enzymes may also play an important role in the regulation of inflammation, a pathological situation with clear links to metabolism. SIRT1 deacetylation of p65 lysine 310 can inhibit the recruitment of the bromodomain-containing coactivator Brd4. Lack of Brd4 recruitment is thought to impair the binding of CDK9 and the recruitment and phosphorylation of RNA polymerase II (PolII), leading to reduced transcription of several proinflammatory mediators such as interleukin IL-1 $\beta$, IL-2, IL-6, TNF $\alpha$, and MMP9 [241].

\section{Obesity-Associated Hypoxia}

Recent studies support a hypoxia response in the adipose tissue in obese animals [91]. Adipose tissue hypoxia (ATH) may provide cellular mechanisms for the development of insulin resistance, chronic inflammation, macrophage infiltration, adiponectin reduction, leptin elevation, adipocytes death, ER stress, and mitochondrial dysfunction in white adipose tissue in obesity $[100,150,253]$. Therefore, ATH might contribute to cancer risk in the obese population. Hypoxia-inducible factor 1 alpha (HIF- $1 \alpha$ ), the most important transcription factor regulated by hypoxia, leads to an elevation of vascularization in tumors [139]. In normoxia, levels are regulated by ubiquitination and subsequent degradation in the proteosome. H1F-1 $\alpha$ upregulation results from decreased ubiquitination induced by EGF, insulin, and IGFs through their PI3K/Akt and MAPK pathways [100]. H1F$1 \alpha$ regulates the transcription of genes that are involved in different aspects of cancer biology, including angiogenesis, cell survival, glucose metabolism, and invasion [254], and has been associated with increased patient mortality [254], poor prognosis, and increased metastasis [255]. Furthermore, HIF$1 \alpha$ inhibition might improve sensitivity of tumors to radiation [256]. In 2005, HIF- $1 \alpha$ was shown to be increased in adipose tissue of obese patient and its expression was reduced after surgery-induced weight loss [257]. The increase in HIF-1 $\alpha$ expression was confirmed in adipose tissue and adipocytes $[91,99,258]$.

HIF- $1 \alpha$ pathways interact with the NF- $\kappa$ B pathway, linking hypoxia to inflammation [256], and activation of NF- $\kappa \mathrm{B}$ complex is a potential mechanism through which inflammation may stimulate cancer development $[42,152]$.

\section{Genetic Susceptibility}

Are genetic factors that predispose to obesity related to the same factors that predispose to certain tumors? Recent studies have made progress mapping obesity-linked genes [259] with those of cancer [260-262]. A few potential overlaps have been found for breast cancer on chromosomes 11p and $16 \mathrm{q}$ and for colorectal cancer on 18q [150]. A recent Scottish case-control study addressing the latter found no association [263], but more studies are required to prove or disprove this hypothesis.

\section{Adipose Stromal Cells}

As tumors develop, they require the development of new vasculature that supplies them with nutrients and oxygen. Mesenchymal stromal cells might be a potential source for the formation of this neovasculature. Bone marrow has been thought to be the main source of circulating progenitor cells, but recent evidence points towards the belief that WAT could be another source [264]. Adipose tissue contains a population of tumor-tropic mesenchymal progenitors, termed adipose stromal cells (ASCs), which engraft in neighboring tumors to form supportive tumor stroma [265]. Abdominal visceral adipose tissue, particularly, may contain a uniquely tumorpromoting population of ASC [265]. When transplanted into mice, adipose stromal cells (ASCs) can serve as vascular adipocyte progenitors that promote tumor growth, perhaps helping explain the obesity-cancer link [266]. ASCs are expanded in obesity and they migrate from endogenous WAT to tumors in several mouse models of cancer [266]. Evidence is starting to accumulate that links ASCs recruited from endogenous adipose tissue by obesity-associated hypoxia and inflammation with tumor growth and development [150] to contribute to tumor growth and development.

\section{Obesity-Related Inflammation}

The links between obesity and inflammation and between chronic inflammation and cancer suggest that inflammation might be important in the obesity-cancer link [146]. In the obese state, adipose tissue is in a chronic state of inflammation. This chronic inflammation is implicated in the emergence of insulin resistance, dyslipidemia, and type 2 diabetes (T2D), as well as comorbidities, including cardiovascular disease and cancer $[146,267,268]$. This inflammation is characterized by increased serum concentrations of C-reactive protein (CRP) [217], interleukin 6 (IL-6), IL8, monocyte chemotactic protein-1 (MCP-1), and tumor necrosis factor alpha (TNF $\alpha$ ) in patients and different animal models of obesity [216, 269-271]. Interestingly, part of the adult obese population remains relatively healthy despite obesity [272-274]. The protective mechanism is attributable in part to a reduced inflammatory signaling and profile [274276]. Brd2 hypomorph mouse studies show that blocking inflammatory signal transduction protects extremely obese animals from insulin resistance, T2D, as well as from cancer [275]. The molecular mechanisms by which obesity-induced chronic inflammation might influence tumorigenesis include increased production of proinflammatory mediators, such as cytokines, chemokines, and reactive oxygen intermediates; increased expression of oncogenes, COX-2 (cyclooxygenase-2), 5-LOX (5-lipoxygenase), and MMPs (matrix metalloproteinases); and proinflammatory transcription factors such as NF- $\kappa$ B, STAT3 (signal transducer and activator of transcription 3), AP-1 (activator protein 1), and HIF-1 $\alpha$ that mediate tumor cell proliferation, transformation, metastasis, survival, invasion, angiogenesis, chemo resistance, and radio resistance [277].

11.1. CRP. CRP is an acute-phase protein secreted mainly by the liver and an unspecific marker for inflammation, 
infection, and tissue injury. Given that adipose tissue secretes proinflammatory mediators, it is not surprising that CRP levels correlate with the amount of adipose tissue. It has been observed that $35 \%$ of obese men and $60 \%$ of obese women with a BMI $>30 \mathrm{~kg} / \mathrm{m}^{2}$ have increased levels of CRP [278]. Moreover, expression of CRP was found in human and animal adipose tissue, showing a twofold increase in obese animals, compared to lean controls [279]. CRP was reported to predict the development of diabetes in both obese men and women [280, 281]. CRP is also associated with an increased risk to develop colorectal, cervical, and ovarian cancer [282], which are cancers that have been associated with obesity. A recent study on obesity and survival after colon cancer (388 colon cancer patients) found that patients who had the highest amounts of serum CRP were significantly more likely to die of colon cancer $(P \leq 0.001)$. The CRP levels were inversely associated with survival in American Joint Committee on Cancer stage II patients $(P=0.038)$, suggesting that CRP could be used to support treatment decisions in this subgroup. They concluded that it is obesityrelated inflammation, rather than obesity itself, that is, linked with poorer survival after a colon cancer diagnosis [283]. All together, these data suggest a potential link between obesity, inflammation and cancer.

11.2. IL-6. IL-6 is a cytokine produced by many tissues in the body, but adipose tissue contributes up to $35 \%$ of the circulating levels of IL-6 [284]. Levels of IL-6 correlate with weight, BMI, waist/hip circumference, waist/hip ratio, and CRP concentration [285] implicating this cytokine in obesity-associated inflammation. IL-6 signaling starts with the IL-6 receptor and subsequent phosphorylation of tumorpromoting transcription factor STAT3, proteins that directly bind to target genes, affecting translation. There is evidence implicating IL-6 in cancer tumorigenesis through the STAT3 pathway [286-288]. IL-6 has been found elevated in several cancers and cancer cell lines including colon, breast, gastrointestinal tract, lymph nodes, skin, lung, ovary, pancreas, prostate, and kidney [289-298], and it is known to promote angiogenesis [173]. One of the most compelling effects of obesity on cancer risk has been on hepatocellular carcinoma or HCC. Park et al. [299] found that obesity enhanced the development of HCC by stimulating the production of tumor-promoting cytokines IL- 6 and TNF that also cause chronic inflammation. Production of these signaling molecules, which are elevated in obese mice and in humans, causes inflammation of the liver and activation of STAT3. This protein in turn activates the formation and growth of liver cancer. STAT3 activation in hepatocytes is essential for DEN-induced HCC development [300] and for obesity-stimulated tumor growth [299]. Ablation of IL6 or TNFR1 blocked obesity-promoted hepatocarcinogenesis [301]. Recently IL-6 has been shown to contribute to systemic insulin resistance [302]. Several cytokines have strong influence on the regulation of insulin resistance in the context of hepatic inflammation. A recent study has shown that IL-6 can inhibit insulin signaling in hepatocytes [303], and insulin resistance is a potential link between obesity and cancer development.
11.3. TNF $\alpha$. Tumor necrosis factor alpha is a cytokine involved in systemic inflammation and is a member of a group of cytokines that stimulate the acute phase reaction. The most abundant cellular sources of TNF $\alpha$ are macrophage and monocyte [304], but it is produced also by a broad variety of cell types, including lymphoid cells, mast cells, endothelial cells, cardiac myocytes, fibroblast, neurons, and adipose tissue $[305,306]$. Obesity leads to infiltration of adipose tissue by macrophages and increased levels in proinflammatory cytokines. The first indication for increased cytokine release in obesity was provided by the identification of increased expression of TNF $\alpha$ in the adipose tissue of obese mice in the early 1990s [307]. TNF $\alpha$ is expressed in and secreted by adipose tissue, its levels correlating with the degree of adiposity [307]. In response to inflammatory stimulation, macrophage or monocyte secretes $\mathrm{TNF} \alpha$ that can induce apoptotic or necrotic cell death of certain tumor cell lines [306]. In addition, TNF $\alpha$ is also capable of inducing cell proliferation and differentiation in many types of cells under certain circumstances $[308,309]$. The increased expression of $\mathrm{TNF} \alpha$ in adipose tissue was considered to be responsible for the development of obesity or diabetes due to the induction of insulin resistance [310] through downregulation of insulin receptors and glucose transporters [42]. TNF $\alpha$ was found to phosphorylate IRS-1 and IRS-2 and therefore interfere in the signaling of the tyrosine kinase of the IR which might also contribute to insulin resistance [139]. To further support this view, studies using mice lacking TNF $\alpha$ function showed protection from obesity-induced insulin resistance [311]. All of previous functional characteristics of TNF $\alpha$ are executed through specific members of the TNF receptor (TNFR) superfamily, mainly TNFR1, the primary receptor for soluble TNF $\alpha$, and TNFR2, the predominant receptor for membrane-associated TNF $\alpha$. These receptors trigger several intracellular signaling pathways, most importantly, the IkB kinase (IKK) and mitogen-activated protein kinase (MAPK) cascades, which govern gene expression through $\mathrm{NF} \kappa \mathrm{B}$ and AP-1 transcription factors, respectively (reviewed in [306]). These signaling pathways, in turn, regulate cell survival, proliferation, or death. Complicated roles for TNF $\alpha$ in cancer have emerged. On the one hand, its anticancer property is mainly through inducing cancer cell death, a process that could be used for cancer therapy. On the other hand, TNF stimulates proliferation, survival, migration, and angiogenesis in most cancer cells that are resistant to TNFinduced cytotoxicity, resulting in tumor promotion. Thus, TNF is a double-edged sword that could be either pro- or antitumorigenic [312].

\section{Obesity, Inflammation, and Esophageal Cancer}

A marked change has been observed in the last decade in esophageal epidemiology. Whereas the incidence rates of esophageal adenocarcinoma have risen in recent decades, they remained stable for esophageal squamous cell carcinoma [313]. This rise in incidence has partly been attributed to the rise in the prevalence of obesity. Some evidence from cohorts and meta-analysis has recently confirmed the association 
between obesity and risk of esophageal adenocarcinoma $[147,314,315]$. Frequent gastroesophageal reflux (GER), central obesity, $H$. pylori eradication, and male gender have been identified as risk factors for Barrett's esophagus (BE), consistently found to be a strong risk factor for esophageal adenocarcinoma (EA) [316]. The best available evidence from population-based analysis suggests that the prevalence of Barrett's is $1.6 \%$ [317]. In addition, nearly half of the patients with Barrett's are asymptomatic [317]. The precise incidence of progression from Barrett's to esophageal adenocarcinoma is not known. The present hypothesis is that obesity promotes reflux, causing chronic inflammation and $\mathrm{BE}$, predisposing to adenocarcinoma [318]. The degree of dysplasia is currently used as a marker for risk of progression to cancer. Intensive acid-suppression and COX-2 inhibition are potential strategies to reduce the risk of progression [317].

\section{Obesity, Inflammation, and Liver Cancer}

Obesity often causes a number of comorbidities, including T2D, nonalcoholic fatty liver disease (NAFLD), and the more severe non-alcoholic steatohepatitis (NASH). Recently, obesity was recognized as a major risk factor for several common types of cancer, of which liver cancer shows a large increase in risk [65]. Several epidemiological and clinical studies have confirmed the importance of obesity as an independent risk factor for hepatocellular carcinoma (HCC), the most common form of liver cancer [319, 320]. Liver inflammation has been shown to be associated with obesityinduced NAFLD, NASH, fibrosis, and cirrhosis, resulting in elevated production of various cytokines and adipokines, which have been implicated in hepatocarcinogenesis [301].

\section{Obesity, Inflammation, and Colon Cancer}

Obesity has been associated with higher risk of colorectal cancer. The association between BMI and risk for colon cancer is positive in men, $\mathrm{RR}=1.24$, but somehow weaker in women, $\mathrm{RR}=1.09$ [230]. The difference could be expected, since abdominal obesity, more common in men, has been shown to be more strongly associated with metabolic abnormalities than gluteofemoral obesity [321]. This hypothesis has been supported by epidemiological evidence that associates increased waist circumference or increased waist-hip ratio with colon cancer risk in men and women, whereas body weight and BMI are associated with colon cancer risk in men but not in women [322]. These epidemiological data also support insulin resistance and subsequent hyperinsulinemia as risk factors for colon cancer [323]. Increased levels of bioavailable insulin-like growth factor- (IGF-) 1, which is known to have cancer promoting effects, are related to hyperinsulinemia [324-326].

In experimental studies, colon cancer has also been associated with several adipokines. For example, leptin, a proinflammatory agent, directly associated with the amount of adipose tissue, is related to insulin resistance and progression of colon cancer in experimental studies [324, 327329]. This observation is supported by population-based studies $[329,330]$ that demonstrated significant associations of leptin with colon cancer risk. By contrast, adiponectin, an anti-inflammatory agent, amount is decreased in obesity and is inversely associated with the development of insulin resistance [331]. There are controversial data relating low plasma adiponectin levels with higher risk of colorectal cancer in men [332, 333]. Moreover, McMillan et al. [334] reported that preoperative CRP above $10 \mathrm{mg} / \mathrm{L}$ was significantly associated with overall mortality $(\mathrm{HR}=2.63 ; 95 \% \mathrm{CI}$, $1.42-4.88)$ and disease-specific mortality ( $\mathrm{HR}=3.47 ; 95 \% \mathrm{CI}$, 1.59-7.60). Several independent studies have demonstrated that CRP is an independent predictor of colorectal cancer survival [335-340]. The Glasgow Prognostic Score (GPS) is a combined score of elevated CRP $(>10 \mathrm{mg} / \mathrm{L})$ and low albumin $(<35 \mathrm{~g} / \mathrm{L})$ and has been demonstrated as a predictive test for poor outcomes in a variety of cancers [341-343]. Increased GPS was significantly associated with reduced survival time of colorectal cancer patients [337, 344, 345]. Furthermore, in a recent study, regular aspirin (a nonsteroidal anti-inflammatory drug) use after diagnosis independently reduced overall mortality $(\mathrm{HR}=0.79 ; 95 \% \mathrm{CI}, 0.65-0.97)$ and colorectal cancer-specific mortality $(\mathrm{HR}=0.71$; 95\% CI, $0.53-$ 0.95) [346].

\section{Obesity, Inflammation, and Breast Cancer}

There is evidence that the association between obesity and breast cancer risk is dependent on the menopausal status, with stronger evidence for postmenopausal women [347]. The association of BMI with postmenopausal breast cancer risk is particularly linked to elevated blood levels of estradiol [348]. Elevated blood concentrations of androgens are also associated with increased risk of breast cancer in both preand postmenopausal women, and thus androgens may be potential candidates linking obesity and breast cancer [347]. In contrast to men, testosterone concentrations are positively related with obesity in women [348]. In premenopausal women, the main site of synthesis of estrogen is the ovary. In postmenopausal women, adipose tissue is the main source of the circulating estrogens. Adipose tissue produces the enzymes aromatase. Therefore, in obese women, there is an increased conversion of the androgens androstenedione and testosterone into the estrogens oestrone and oestradiol, respectively, by aromatase.

Another potential link is that obesity, being associated with metabolic syndrome, results in increased circulating levels of insulin and insulin-like growth factor (IGF), which are associated to carcinogenesis. Several studies have shown the association between hyperinsulinemia, measured as high circulating levels of serum C-peptide, with elevated risk of postmenopausal breast cancer [349-352]. In addition, insulin resistance is an adverse prognostic factor for breast cancer [353].

Adipokines might also be important contributors to the association between obesity and breast cancer risk. Women with breast cancer have higher leptin plasma levels and mRNA expression in adipose tissue as compared to healthy subjects, and the blood levels of estradiol increase 
proportional to those of leptin [354]. Recent studies have demonstrated that leptin can modulate the activators of STAT3, AP-1, extracellular signal regulated kinase-2 (ERK2), and MAPK, all involved in the regulation of proliferation and survival mechanisms, as well as aromatase expression, estrogen synthesis, and ER activation [355, 356]. Furthermore, leptin interferes with insulin signaling, and plasma levels of leptin directly correlate with the degree of insulin resistance in patients with T2D [357], whose association with breast carcinoma has been well studied. Adiponectin, on the other hand, has opposite function to leptin. For example, adiponectin inhibits the leptin-induced production of macrophage TNF $\alpha$ [358]. Studies confirm a significant inverse correlation between serum adiponectin levels, breast cancer risk, and poor prognosis, independently from hormone receptor status [359]. Adiponectin inhibits the proliferation of several cell types and is a negative regulator of angiogenesis [360]. Furthermore, it has been shown that adiponectin activates the PPAR $\gamma$ pathway, previously demonstrated to be important in the expression of BRCA1, a DNA damage repair protein [361]. Among the adipokines, an emerging central role in the breast cancer pathogenesis and prognosis has been recently attributed to the inflammatory mediators TNF $\alpha$ and IL- 6 . TNF $\alpha$ regulates IL- 6 synthesis and aromatase expression in the adipose tissue [362], and it has been implicated in the development of insulin resistance, all potential promoters of breast tumorigenesis. Adipose tissue contributes up to $35 \%$ of the circulating levels of IL-6 [284]. One of the impacts of high IL-6 levels is an increase in serum CRP, an indicator of inflammation. IL-6 increases following menopause in healthy women [211]. A study by Slattery et al. found a significant association between high waist-to-hip ratio, a specific IL- 6 genotype, and an increased risk of breast cancer in postmenopausal women [363]. In a recent study, adipocytes isolated from breast tumor samples overexpressed IL- 6 and this was associated with tumors of larger size and with lymph-node involvement [364], implicating its potential role in invasion and metastasis. Moreover, systemic chronic inflammation mediated by IL- 6 may increase the risk of breast cancer recurrence and affect its prognosis [365].

\section{Obesity, Inflammation, and Endometrial Cancer}

There is a very strong association, 2.5-3.0-fold increase in risk, between obesity and endometrial carcinoma $[225,314]$. Similar to breast cancer, estrogen plays an important role in this association. Several epidemiological studies have shown a link between high levels of plasma estrone and estradiol and risk for endometrial cancer in postmenopausal women [347]. Furthermore, besides a rise in estrogens and androgens, excess weight leads to a decrease in plasma sex hormone-binding globulin [202]. In a multicenter prospective study in postmenopausal women [366], circulating estrogens and androgens were found to be positively associated with endometrial cancer risk, and an inverse association was reported for sex hormone-binding globulin. Moreover, inflammatory markers known to play an important role in the development of insulin resistance, hyperglycemia, and T2D [367] are risk factors for endometrial cancer [202]. For example, increased IL-6 concentrations have been reported in patients with endometrial carcinoma [368-371], and more recently, IL-6, CRP, and IL1Ra were reported to be significantly associated with endometrial cancer risk in a prospective study [372]. Furthermore, NF- $\kappa$ B, transcription factor involved in the immune and inflammatory response, is aberrantly expressed in a majority of endometrial cancer tumors $[373,374]$. One mechanism for the inflammation-mediated association between obesity and endometrial cancer could be the modulation of aromatase activity by cytokines within the adipose tissue [375].

\section{Conclusions}

The links between obesity and inflammation and between chronic inflammation and cancer suggest that inflammation might be important in the obesity-cancer link. Changes in the adipose tissue during the process of going from lean to obese, including modulation of adipokine levels, hypoxia, ROS, FFA, and ER stress, might lead to a chronic state of inflammation in the obese individual. The increased risk of obesityrelated cancers could be mediated in part by these changes in the adipose tissue. Some of the most important elements of this association are, among others, insulin resistance; overexpression of leptin, inflammatory cytokines, sex hormones, transcriptions factors like NF- $\kappa \mathrm{B}, \mathrm{AP}-1, \mathrm{STAT} 3$, and oxidative stress; and downregulation of the expression of antiinflammatory factors like adiponectin and $\operatorname{PPAR} \gamma$, which disrupt the balance between cell proliferation and apoptosis. Accumulating evidence indicates that chronic inflammatory states in the obese might be associated with esophageal, liver, colon, postmenopausal breast, and endometrial cancers. The association between obesity, inflammation, and other cancers like prostate, renal, gastric, pancreatic, and gallbladder has been addressed in other papers. As more data accumulates and the molecular mechanisms between some of these factors and carcinogenesis start to unravel, the prospect of antiinflammatory cancer prevention becomes an important goal in research.

\section{References}

[1] E. Shacter and S. A. Weitzman, "Chronic inflammation and cancer," Oncology, vol. 16, no. 2, pp. 217-232, 2002.

[2] D. Hanahan and R. A. Weinberg, "The hallmarks of cancer," Cell, vol. 100, no. 1, pp. 57-70, 2000.

[3] S. Rakoff-Nahoum, "Why cancer and inflammation?" Yale Journal of Biology and Medicine, vol. 79, no. 3-4, pp. 123-130, 2006.

[4] M. E. Ramos-Nino, J. R. Testa, D. A. Altomare et al., "Cellular and molecular parameters of mesothelioma," Journal of Cellular Biochemistry, vol. 98, no. 4, pp. 723-734, 2006.

[5] C. D. Woodworth, B. T. Mossman, and J. E. Craighead, "Squamous metaplasia of the respiratory tract. Possible pathogenic role in asbestos-associated bronchogenic carcinoma," Laboratory Investigation, vol. 48, no. 5, pp. 578-584, 1983. 
[6] P. T. Scheepers and R. C. Vermeulen, "Diesel engine exhaust classified as a human lung carcinogen. How will this affect occupational exposures?" Occupational and Environmental Medicine, vol. 69, no. 10, pp. 691-693, 2012.

[7] D. P. Zandberg, R. Bhargava, S. Badin, and K. J. Cullen, “The role of human papillomavirus in nongenital cancers," A Cancer Journal for Clinicians, vol. 63, no. 1, pp. 57-81, 2013.

[8] E. Smolle, E. Zöhrer, K. Bettermann, and J. Haybaeck, "Viral hepatitis induces hepatocellular cancer: what can we learn from epidemiology comparing iran and worldwide findings?" Hepatitis Monthly, vol. 12, no. 10 HCC, Article ID e7879, 2012.

[9] W. Gu, C. Chen, and K. N. Zhao, "Obesity-associated endometrial and cervical cancers," Frontiers in Bioscience, vol. E5, pp. 109-118, 2013.

[10] E. Orgel and S. D. Mittelman, "The links between insulin resistance, diabetes, and cancer," Current Diabetes Reports, vol. 13, no. 2, pp. 213-222, 2013.

[11] R. N. Saladi and A. N. Persaud, "The causes of skin cancer: a comprehensive review," Drugs of Today, vol. 41, no. 1, pp. 37-53, 2005.

[12] N. E. Sounni and A. Noel, "Targeting the tumor microenvironment for cancer therapy," Clinical Chemistry, vol. 59, no. 1, pp. 85-93, 2013.

[13] F. Balkwill and A. Mantovani, "Inflammation and cancer: back to Virchow?” The Lancet, vol. 357, no. 9255, pp. 539-545, 2001.

[14] D. W. Kamp, E. Shacter, and S. A. Weitzman, "Chronic inflammation and cancer: the role of the mitochondria," Oncology, vol. 25, no. 5, pp. 400-413, 2011.

[15] L. M. Coussens and Z. Werb, "Inflammation and cancer," Nature, vol. 420, no. 6917, pp. 860-867, 2002.

[16] D. B. Vendramini-Costa and J. E. Carvalho, "Molecular link mechanisms between inflammation and cancer," Current Pharmaceutical Design, vol. 18, no. 26, pp. 3831-3852, 2012.

[17] H. Kuper, H. O. Adami, and D. Trichopoulos, "Infections as a major preventable cause of human cancer," Journal of Internal Medicine, vol. 248, no. 3, pp. 171-183, 2000.

[18] A. Mantovani, P. Allavena, A. Sica, and F. Balkwill, "Cancerrelated inflammation," Nature, vol. 454, no. 7203, pp. 436-444, 2008.

[19] J. Galon, A. Costes, F. Sanchez-Cabo et al., “Type, density, and location of immune cells within human colorectal tumors predict clinical outcome," Science, vol. 313, no. 5795, pp. 19601964, 2006.

[20] C. H. Koehne and R. N. Dubois, "COX-2 inhibition and colorectal cancer," Seminars in Oncology, vol. 31, no. 7, pp. 1221, 2004.

[21] F. M. Shebl, L. C. Sakoda, A. Black, J. Koshiol, R. Grubb, T. R. Church et al., "Aspirin but not ibuprofen use is associated with reduced risk of prostate cancer: a PLCO study, British Journal of Cancer, vol. 107, no. 1, pp. 207-214, 2012.

[22] A. J. Walker, M. J. Grainge, and T. R. Card, "Aspirin and other non-steroidal anti-inflammatory drug use and colorectal cancer survival: a cohort study," British Journal of Cancer, vol. 107, no. 9, pp. 1602-1607, 2012.

[23] H. H. Lee, Y. T. Tsan, W. C. Ho, M. H. Lin, C. H. Lee, C. D. Tseng et al., "Angiotensin-converting enzyme inhibitors enhance the effect of cyclooxygenase inhibitors on breast cancer: a nationwide case-control study," Journal of Hypertension, vol. 30, no. 12, pp. 2432-2439, 2012.

[24] M. E. Ramos-Nino, C. D. MacLean, and B. Littenberg, "Association of angiotensin-converting enzyme inhibitor therapy and comorbidity in diabetes: results from the Vermont diabetes information system," BMC Endocrine Disorders, vol. 8, article 17, 2008.

[25] C. E. Holmes, M. E. Ramos-Nino, and B. Littenberg, "An association between anti-platelet drug use and reduced cancer prevalence in diabetic patients: results from the Vermont Diabetes Information System Study," BMC Cancer, vol. 10, article 289, 2010.

[26] L. Radoi, S. Paget-Bailly, D. Cyr, A. Papadopoulos, F. Guida, A. Schmaus et al., "Tobacco smoking, alcohol drinking and risk of oral cavity cancer by subsite: results of a French populationbased case-control study, the ICARE study," European Journal of Cancer Prevention, vol. 22, no. 3, pp. 268-276, 2013.

[27] L. Radoi and D. Luce, "A review of risk factors for oral cavity cancer: the importance of a standardized case definition," Community Dentistry and Oral Epidemiology, vol. 41, no. 2, pp. 97-109, 2013.

[28] S. S. Hecht, "Lung carcinogenesis by tobacco smoke," International Journal of Cancer, vol. 131, no. 12, pp. 2724-2732, 2012.

[29] P. Grewal and V. A. Viswanathen, "Liver cancer and alcohol," Clinical Liver Disease, vol. 16, no. 4, pp. 839-850, 2012.

[30] B. J. Vennervald and K. Polman, "Helminths and malignancy," Parasite Immunology, vol. 31, no. 11, pp. 686-696, 2009.

[31] G. Khan, "Epstein-Barr virus, cytokines, and inflammation: a cocktail for the pathogenesis of Hodgkin's lymphoma?" Experimental Hematology, vol. 34, no. 4, pp. 399-406, 2006.

[32] A. Lamb and L. F. Chen, "Role of the Helicobacter pyloriinduced inflammatory response in the development of gastric cancer," Journal of Cellular Biochemistry, vol. 114, no. 3, pp. 491497, 2013.

[33] F. Liotti, C. Visciano, and R. M. Melillo, "Inflammation in thyroid oncogenesis," American Journal of Cancer Research, vol. 2, no. 3, pp. 286-297, 2012.

[34] A. Nicholson and J. Jankowski, "Acid reflux and oesophageal cancer," Recent Results in Cancer Research, vol. 185, pp. 65-82, 2011.

[35] K. S. Sfanos and A. M. De Marzo, "Prostate cancer and inflammation: the evidence," Histopathology, vol. 60, no. 1, pp. 199-215, 2012.

[36] S. Ghosh and K. Ashcraft, "An IL-6 link between obesity and cancer," Frontiers in Bioscience, vol. 5, pp. 461-478, 2013.

[37] E. L. Heinrich, T. C. Walser, K. Krysan et al., "The inflammatory tumor microenvironment, epithelial mesenchymal transition and lung carcinogenesis," Cancer Microenviron, vol. 5, no. 1, pp. 5-18, 2012.

[38] K. E. Wellen and G. S. Hotamisligil, "Inflammation, stress, and diabetes," Journal of Clinical Investigation, vol. 115, no. 5, pp. 11111119, 2005.

[39] M. I. Goran and T. L. Alderete, "Targeting adipose tissue inflammation to treat the underlying basis of the metabolic complications of obesity," Nestlé Nutrition Institute Workshop Series, vol. 73, pp. 49-66, 2012.

[40] S. D. Hursting and S. M. Dunlap, "Obesity, metabolic dysregulation, and cancer: a growing concern and an inflammatory (and microenvironmental) issue," Annals of the New York Academy of Sciences, vol. 1271, pp. 82-87, 2012.

[41] R. B. Ervin, "Prevalence of metabolic syndrome among adults 20 years of age and over, by sex, age, race and ethnicity, and body mass index: United States, 2003-2006," National Health Statistics Reports, no. 13, pp. 1-7, 2009. 
[42] A. E. Harvey, L. M. Lashinger, and S. D. Hursting, "The growing challenge of obesity and cancer: an inflammatory issue," Annals of the New York Academy of Sciences, vol. 1229, no. 1, pp. 45-52, 2011.

[43] N. Halberg, I. Wernstedt-Asterholm, and P. E. Scherer, "The adipocyte as an endocrine cell," Endocrinology and Metabolism Clinics of North America, vol. 37, no. 3, pp. 753-768, 2008.

[44] S. Gesta, Y. H. Tseng, and C. R. Kahn, "Developmental origin of fat: tracking obesity to its source," Cell, vol. 131, no. 2, pp. 242256, 2007.

[45] S. E. Wozniak, L. L. Gee, M. S. Wachtel, and E. E. Frezza, "Adipose tissue: the new endocrine organ? a review article," Digestive Diseases and Sciences, vol. 54, no. 9, pp. 1847-1856, 2009.

[46] C. E. Juge-Aubry, E. Henrichot, and C. A. Meier, "Adipose tissue: a regulator of inflammation," Best Practice and Research, vol. 19, no. 4, pp. 547-566, 2005.

[47] S. A. Porter, J. M. Massaro, U. Hoffmann, R. S. Vasan, C. J. O'Donnel, and C. S. Fox, "Abdominal subcutaneous adipose tissue: a protective fat depot?” Diabetes Care, vol. 32, no. 6, pp. 1068-1075, 2009.

[48] G. Fruhbeck, J. Gómez-Ambrosi, F. J. Muruzábal, and M. A. Burrell, "The adipocyte: a model for integration of endocrine and metabolic signaling in energy metabolism regulation," American Journal of Physiology, vol. 280, no. 6, pp. E827-E847, 2001.

[49] A. Dicker, K. Le Blanc, G. Åström et al., "Functional studies of mesenchymal stem cells derived from adult human adipose tissue," Experimental Cell Research, vol. 308, no. 2, pp. 283-290, 2005.

[50] J. T. Crossno, S. M. Majka, T. Grazia, R. G. Gill, and D. J. Klemm, "Rosiglitazone promotes development of a novel adipocyte population from bone marrow-derived circulating progenitor cells," Journal of Clinical Investigation, vol. 116, no. 12, pp. 32203228, 2006.

[51] G. J. Hausman and D. B. Hausman, "Search for the preadipocyte progenitor cell," Journal of Clinical Investigation, vol. 116, no. 12, pp. 3103-3106, 2006.

[52] K. Jaworski, E. Sarkadi-Nagy, R. E. Duncan, M. Ahmadian, and H. S. Sul, "Regulation of Triglyceride Metabolism. IV. Hormonal regulation of lipolysis in adipose tissue," American Journal of Physiology, vol. 293, no. 1, pp. G1-G4, 2007.

[53] A. S. Greenberg, J. J. Egan, S. A. Wek, N. B. Garty, E. J. Blanchette-Mackie, and C. Londos, "Perilipin, a major hormonally regulated adipocyte-specific phosphoprotein associated with the periphery of lipid storage droplets," Journal of Biological Chemistry, vol. 266, no. 17, pp. 11341-11346, 1991.

[54] R. A. Weisiger, "Cytosolic fatty acid binding proteins catalyze two distinct steps in intracellular transport of their ligands," Molecular and Cellular Biochemistry, vol. 239, no. 1-2, pp. 35-43, 2002.

[55] R. A. Weisiger and S. D. Zucker, "Transfer of fatty acids between intracellular membranes: roles of soluble binding proteins, distance, and time," American Journal of Physiology, vol. 282, no. 1, pp. G105-G115, 2002.

[56] N. S. Tan, N. S. Shaw, N. Vinckenbosch et al., "Selective cooperation between fatty acid binding proteins and peroxisome proliferator-activated receptors in regulating transcription," Molecular and Cellular Biology, vol. 22, no. 14, pp. 5114-5127, 2002.
[57] V. Ceperuelo-Mallafré, M. Miranda, M. R. Chacón et al., "Adipose tissue expression of the glycerol channel aquaporin7 gene is altered in severe obesity but not in type 2 diabetes," Journal of Clinical Endocrinology and Metabolism, vol. 92, no. 9, pp. 3640-3645, 2007.

[58] A. H. Ali, C. Koutsari, M. Mundi, M. D. Stegall, J. K. Heimbach, S. J. Taler et al., "Free fatty acid storage in human visceral and subcutaneous adipose tissue: role of adipocyte proteins," Diabetes, vol. 60, no. 9, pp. 2300-2307, 2011.

[59] L. A. Tartaglia, M. Dembski, X. Weng et al., "Identification and expression cloning of a leptin receptor, OB-R," Cell, vol. 83, no. 7, pp. 1263-1271, 1995.

[60] J. D. Mcgarry, "Does leptin lighten the problem of obesity?" Current Biology, vol. 5, no. 12, pp. 1342-1344, 1995.

[61] R. C. Frederich, A. Hamann, S. Anderson, B. Lollmann, B. B. Lowell, and J. S. Flier, "Leptin levels reflect body lipid content in mice: evidence for diet-induced resistance to leptin action," Nature Medicine, vol. 1, no. 12, pp. 1311-1314, 1995.

[62] M. Mapfei, J. Halaas, E. Ravussin et al., "Leptin levels in human and rodent: measurement of plasma leptin and ob RNA in obese and weight-reduced subjects," Nature Medicine, vol. 1, no. 11, pp. 1155-1161, 1995.

[63] O. A. Macdougald, C. S. Hwang, H. Fan, and M. D. Lane, "Regulated expression of the obese gene product (leptin) in white adipose tissue and 3T3-L1 adipocytes," Proceedings of the National Academy of Sciences of the United States of America, vol. 92, no. 20, pp. 9034-9037, 1995.

[64] V. Koivisto, "Reducing weight with leptin," Duodecim, vol. 111, no. 18, pp. 1731-1733, 1995.

[65] D. W. Haslam and W. P. T. James, “Obesity," The Lancet, vol. 366, no. 9492, pp. 1197-1209, 2005.

[66] M. Zeyda and T. M. Stulnig, "Adipose tissue macrophages," Immunology Letters, vol. 112, no. 2, pp. 61-67, 2007.

[67] M. Zeyda, D. Farmer, J. Todoric et al., "Human adipose tissue macrophages are of an anti-inflammatory phenotype but capable of excessive pro-inflammatory mediator production," International Journal of Obesity, vol. 31, no. 9, pp. 1420-1428, 2007.

[68] S. Gordon, "Macrophage heterogeneity and tissue lipids," Journal of Clinical Investigation, vol. 117, no. 1, pp. 89-93, 2007.

[69] D. E. Moller and J. P. Berger, "Role of PPARs in the regulation of obesity-related insulin sensitivity and inflammation," International Journal of Obesity, vol. 27, no. 3, pp. S17-S21, 2003.

[70] S. B. Joseph, A. Castrillo, B. A. Laffitte, D. J. Mangelsdorf, and P. Tontonoz, "Reciprocal regulation of inflammation and lipid metabolism by liver X receptors," Nature Medicine, vol. 9, no. 2, pp. 213-219, 2003.

[71] C. Caruso, C. R. Balistreri, and G. Candore, "The role of adipose tissue and adipokines in obesity-related inflammatory diseases," Mediators of Inflammation, vol. 2010, Article ID 802078, 2010.

[72] C. N. Lumeng, J. B. Delproposto, D. J. Westcott, and A. R. Saltiel, "Phenotypic switching of adipose tissue macrophages with obesity is generated by spatiotemporal differences in macrophage subtypes," Diabetes, vol. 57, no. 12, pp. 3239-3246, 2008.

[73] V. Bourlier, A. Zakaroff-Girard, A. Miranville et al., "Remodeling phenotype of human subcutaneous adipose tissue macrophages," Circulation, vol. 117, no. 6, pp. 806-815, 2008.

[74] V. Subramanian and A. W. Ferrante, "Obesity, inflammation, and macrophages," Nestle Nutrition Workshop Series, vol. 63, pp. 151-162, 2009. 
[75] J. Chudek and A. Wiçcek, "Adipose tissue, inflammation and endothelial dysfunction," Pharmacological Reports, vol. 58, pp. 81-88, 2006.

[76] C. Sengenès, A. Miranville, K. Lolmède, C. A. Curat, and A. Bouloumié, "The role of endothelial cells in inflamed adipose tissue," Journal of Internal Medicine, vol. 262, no. 4, pp. 415-421, 2007.

[77] S. Hummasti and G. S. Hotamisligil, "Endoplasmic reticulum stress and inflammation in obesity and diabetes," Circulation Research, vol. 107, no. 5, pp. 579-591, 2010.

[78] M. Lafontan and M. Berlan, "Do regional differences in adipocyte biology provide new pathophysiological insights?" Trends in Pharmacological Sciences, vol. 24, no. 6, pp. 276-283, 2003.

[79] K. L. Spalding, E. Arner, P. O. Westermark et al., "Dynamics of fat cell turnover in humans," Nature, vol. 453, no. 7196, pp. 783787, 2008.

[80] T. Skurk, C. Alberti-Huber, C. Herder, and H. Hauner, "Relationship between adipocyte size and adipokine expression and secretion," Journal of Clinical Endocrinology and Metabolism, vol. 92, no. 3, pp. 1023-1033, 2007.

[81] M. Jernås, J. Palming, K. Sjöholm et al., "Separation of human adipocytes by size: hypertrophic fat cells display distinct gene expression," The FASEB Journal, vol. 20, no. 9, pp. 1540-1542, 2006.

[82] R. H. Unger, "Lipotoxic diseases," Annual Review of Medicine, vol. 53, pp. 319-336, 2002.

[83] S. Taleb, R. Cancello, K. Clément, and D. Lacasa, "Cathepsin S promotes human preadipocyte differentiation: possible involvement of fibronectin degradation," Endocrinology, vol. 147, no. 10, pp. 4950-4959, 2006.

[84] Y. Xiao, H. Junfeng, L. Tianhong, W. Lu, C. Shulin, Z. Yu et al., "Cathepsin $\mathrm{K}$ in adipocyte differentiation and its potential role in the pathogenesis of obesity," The Journal of Clinical Endocrinology \& Metabolism, vol. 91, no. 11, pp. 4520-4527, 2006.

[85] J. G. Neels, T. Thinnes, and D. J. Loskutoff, "Angiogenesis in an in vivo model of adipose tissue development," FASEB Journal, vol. 18, no. 9, pp. 983-985, 2004.

[86] S. Nishimura, I. Manabe, M. Nagasaki et al., "Adipogenesis in obesity requires close interplay between differentiating adipocytes, stromal cells, and blood vessels," Diabetes, vol. 56, no. 6, pp. 1517-1526, 2007.

[87] E. Bråkenhielm, R. Cao, B. Gao et al., "Angiogenesis inhibitor, TNP-470, prevents diet induced and genetic obesity in mice," Circulation Research, vol. 94, no. 12, pp. 1579-1588, 2004.

[88] M. G. Kolonin, P. K. Saha, L. Chan, R. Pasqualini, and W. Arap, "Reversal of obesity by targeted ablation of adipose tissue," Nature Medicine, vol. 10, no. 6, pp. 625-632, 2004.

[89] M. A. Rupnick, D. Panigrahy, C. Y. Zhang et al., "Adipose tissue mass can be regulated through the vasculature," Proceedings of the National Academy of Sciences of the United States of America, vol. 99, no. 16, pp. 10730-10735, 2002.

[90] N. Hosogai, A. Fukuhara, K. Oshima, Y. Miyata, S. Tanaka, K. Segawa et al., "Adipose tissue hypoxia in obesity and its impact on adipocytokine dysregulation," Diabetes, vol. 56, no. 4, pp. 901-911, 2007.

[91] J. Ye, Z. Gao, J. Yin, and Q. He, "Hypoxia is a potential risk factor for chronic inflammation and adiponectin reduction in adipose tissue of ob/ob and dietary obese mice," American Journal of Physiology, vol. 293, no. 4, pp. E1118-E1128, 2007.
[92] M. E. Rausch, S. Weisberg, P. Vardhana, and D. V. Tortoriello, "Obesity in C57BL/6J mice is characterized by adipose tissue hypoxia and cytotoxic T-cell infiltration," International Journal of Obesity, vol. 32, no. 3, pp. 451-463, 2008.

[93] P. Wang, E. Mariman, J. Keijer et al., "Profiling of the secreted proteins during 3T3-L1 adipocyte differentiation leads to the identification of novel adipokines," Cellular and Molecular Life Sciences, vol. 61, no. 18, pp. 2405-2417, 2004.

[94] J. V. Silha, M. Krsek, P. Sucharda, and L. J. Murphy, "Angiogenic factors are elevated in overweight and obese individuals," International Journal of Obesity, vol. 29, no. 11, pp. 1308-1314, 2005.

[95] C. H. Cho, Y. J. Koh, J. Han et al., "Angiogenic role of LYVE1-positive macrophages in adipose tissue," Circulation Research, vol. 100, no. 4, pp. e47-e57, 2007.

[96] C. N. Lumeng, J. L. Bodzin, and A. R. Saltiel, "Obesity induces a phenotypic switch in adipose tissue macrophage polarization," Journal of Clinical Investigation, vol. 117, no. 1, pp. 175-184, 2007.

[97] P. Trayhurn and I. S. Wood, "Adipokines: inflammation and the pleiotropic role of white adipose tissue," British Journal of Nutrition, vol. 92, no. 3, pp. 347-355, 2004.

[98] J. Yin, Z. Gao, Q. He, D. Zhou, Z. Guo, and J. Ye, "Role of hypoxia in obesity-induced disorders of glucose and lipid metabolism in adipose tissue," American Journal of Physiology, vol. 296, no. 2, pp. E333-E342, 2009.

[99] B. Wang, I. S. Wood, and P. Trayhurn, "Dysregulation of the expression and secretion of inflammation-related adipokines by hypoxia in human adipocytes," Pflugers Archiv European Journal of Physiology, vol. 455, no. 3, pp. 479-492, 2007.

[100] J. Ye, "Emerging role of adipose tissue hypoxia in obesity and insulin resistance," International Journal of Obesity, vol. 33, no. 1, pp. 54-66, 2009.

[101] J. Tang, H. Yan, and S. Zhuang, "Inflammation and oxidative stress in obesity-related glomerulopathy," International Journal of Nephrology, vol. 2012, Article ID 608397, 11 pages, 2012.

[102] S. Furukawa, T. Fujita, M. Shimabukuro et al., "Increased oxidative stress in obesity and its impact on metabolic syndrome," Journal of Clinical Investigation, vol. 114, no. 12, pp. 1752-1761, 2004.

[103] J. F. Keaney, Jr, M. G. Larson et al. et al., "Obesity and systemic oxidative stress: clinical correlates of oxidative stress in the Framingham Study," Arteriosclerosis, Thrombosis, and Vascular Biology, vol. 23, no. 3, pp. 434-439, 2003.

[104] H. K. Vincent and A. G. Taylor, "Biomarkers and potential mechanisms of obesity-induced oxidant stress in humans," International Journal of Obesity, vol. 30, no. 3, pp. 400-418, 2006.

[105] E. Pihl, K. Zilmer, T. Kullisaar, C. Kairane, A. Mägi, and M. Zilmer, "Atherogenic inflammatory and oxidative stress markers in relation to overweight values in male former athletes," International Journal of Obesity, vol. 30, no. 1, pp. 141-146, 2006.

[106] S. J. Piva, M. M. M. F. Duarte, I. B. M. Da Cruz et al., "Ischemiamodified albumin as an oxidative stress biomarker in obesity," Clinical Biochemistry, vol. 44, no. 4, pp. 345-347, 2011.

[107] N. Gletsu-Miller, J. M. Hansen, D. P. Jones et al., "Loss of total and visceral adipose tissue mass predicts decreases in oxidative stress after weight-loss surgery," Obesity, vol. 17, no. 3, pp. 439446, 2009.

[108] C. Chrysohoou, D. B. Panagiotakos, C. Pitsavos et al., "The implication of obesity on total antioxidant capacity in apparently healthy men and women: the ATTICA study," Nutrition, Metabolism and Cardiovascular Diseases, vol. 17, no. 8, pp. 590597, 2007. 
[109] J. Hartwich, J. Góralska, D. Siedlecka, A. Gruca, M. Trzos, and A. Dembinska-Kiec, "Effect of supplementation with vitamin $\mathrm{E}$ and $\mathrm{C}$ on plasma hsCRP level and cobalt-albumin binding score as markers of plasma oxidative stress in obesity," Genes and Nutrition, vol. 2, no. 1, pp. 151-154, 2007.

[110] R. Cancello and K. Clément, "Is obesity an inflammatory illness? Role of low-grade inflammation and macrophage infiltration in human white adipose tissue," BJOG: An International Journal of Obstetrics and Gynaecology, vol. 113, no. 10, pp. 11411147, 2006.

[111] F. Lago, C. Dieguez, J. Gómez-Reino, and O. Gualillo, "Adipokines as emerging mediators of immune response and inflammation," Nature Clinical Practice Rheumatology, vol. 3, no. 12, pp. 716-724, 2007.

[112] M. H. Fonseca-Alaniz, J. Takada, M. I. Alonso-Vale, and F. B. Lima, "Adipose tissue as an endocrine organ: from theory to practice," Jornal de Pediatria, vol. 83, no. 5, pp. S192-203, 2007.

[113] A. Fernandez-Sanchez, E. Madrigal-Santillán, M. Bautista, J. Esquivel-Soto, Á. Morales-González, C. Esquivel-Chirino et al., "Inflammation, oxidative stress, and obesity," International Journal of Molecular Sciences, vol. 12, no. 5, pp. 3117-3132, 2011.

[114] J. D. Morrow, "Is oxidant stress a connection between obesity and atherosclerosis?" Arteriosclerosis, Thrombosis, and Vascular Biology, vol. 23, no. 3, pp. 368-370, 2003.

[115] S. De Ferranti and D. Mozaffarian, "The perfect storm: obesity, adipocyte dysfunction, and metabolic consequences," Clinical Chemistry, vol. 54, no. 6, pp. 945-955, 2008.

[116] C. Yu, Y. Chen, G. W. Cline et al., "Mechanism by which fatty acids inhibit insulin activation of insulin receptor substrate1 (IRS-1)-associated phosphatidylinositol 3-kinase activity in muscle," Journal of Biological Chemistry, vol. 277, no. 52, pp. 50230-50236, 2002.

[117] N. I. Khan, L. Naz, and G. Yasmeen, "Obesity: an independent risk factor for systemic oxidative stress," Pakistan Journal of Pharmaceutical Sciences, vol. 19, no. 1, pp. 62-65, 2006.

[118] X. Shi, A. Burkart, S. M. Nicoloro, M. P. Czech, J. Straubhaar, and S. Corvera, "Paradoxical effect of mitochondrial respiratory chain impairment on insulin signaling and glucose transport in adipose cells," Journal of Biological Chemistry, vol. 283, no. 45, pp. 30658-30667, 2008.

[119] C. Jiang, A. T. Ting, and B. Seed, "PPAR- $\gamma$ agonists inhibit production of monocyte inflammatory cytokines," Nature, vol. 391, no. 6662, pp. 82-86, 1998.

[120] J. B. Seo, H. M. Moon, W. S. Kim et al., "Activated liver X receptors stimulate adipocyte differentiation through induction of peroxisome proliferator-activated receptor $\gamma$ expression," Molecular and Cellular Biology, vol. 24, no. 8, pp. 3430-3444, 2004.

[121] C. K. Glass and J. M. Olefsky, "Inflammation and lipid signaling in the etiology of insulin resistance," Cell Metabolism, vol. 15, no. 5, pp. 635-645, 2012.

[122] C. B. Clish, J. A. O’Brien, K. Gronert, G. L. Stahl, N. A. Petasis, and C. N. Serhan, "Local and systemic delivery of a stable aspirin-triggered lipoxin prevents neutrophil recruitment in vivo," Proceedings of the National Academy of Sciences of the United States of America, vol. 96, no. 14, pp. 8247-8252, 1999.

[123] A. González-Périz, R. Horrillo, N. Ferré et al., "Obesity-induced insulin resistance and hepatic steatosis are alleviated by $\omega-3$ fatty acids: a role for resolvins and protectins," FASEB Journal, vol. 23, no. 6, pp. 1946-1957, 2009.
[124] C. Godson and H. R. Brady, "Lipoxins: novel anti-inflammatory therapeutics?" Current Opinion in Investigational Drugs, vol. 1, no. 3, pp. 380-385, 2000.

[125] M. J. Gething and J. Sambrook, "Protein folding in the cell," Nature, vol. 355, no. 6355, pp. 33-45, 1992.

[126] U. Özcan, Q. Cao, E. Yilmaz et al., "Endoplasmic reticulum stress links obesity, insulin action, and type 2 diabetes," Science, vol. 306, no. 5695, pp. 457-461, 2004.

[127] Y. Nakatani, H. Kaneto, D. Kawamori et al., "Involvement of endoplasmic reticulum stress in insulin resistance and diabetes," Journal of Biological Chemistry, vol. 280, no. 1, pp. 847-851, 2005.

[128] M. F. Gregor and G. S. Hotamisligil, "Adipocyte stress: the endoplasmic reticulum and metabolic disease," Journal of Lipid Research, vol. 48, no. 9, pp. 1905-1914, 2007.

[129] G. S. Hotamisligil, "Endoplasmic reticulum stress and the inflammatory basis of metabolic disease," Cell, vol. 140, no. 6, pp. 900-917, 2010.

[130] H. P. Harding, Y. Zhang, A. Bertolotti, H. Zeng, and D. Ron, "Perk is essential for translational regulation and cell survival during the unfolded protein response," Molecular Cell, vol. 5, no. 5, pp. 897-904, 2000.

[131] Y. Ma, J. W. Brewer, J. Alan Diehl, and L. M. Hendershot, “Two distinct stress signaling pathways converge upon the CHOP promoter during the mammalian unfolded protein response," Journal of Molecular Biology, vol. 318, no. 5, pp. 1351-1365, 2002.

[132] C. Sidrauski and P. Walter, "The transmembrane kinase Irelp is a site-specific endonuclease that initiates mRNA splicing in the unfolded protein response," Cell, vol. 90, no. 6, pp. 1031-1039, 1997.

[133] J. Shen, X. Chen, L. Hendershot, and R. Prywes, "ER stress regulation of ATF6 localization by dissociation of BiP/GRP78 binding and unmasking of golgi localization signals," Developmental Cell, vol. 3, no. 1, pp. 99-111, 2002.

[134] N. Kawasaki, R. Asada, A. Saito, S. Kanemoto, and K. Imaizumi, "Obesity-induced endoplasmic reticulum stress causes chronic inflammation in adipose tissue," Scientific Reports, vol. 2, article 799, 2012.

[135] M. Cnop, F. Foufelle, and L. A. Velloso, "Endoplasmic reticulum stress, obesity and diabetes," Trends in Molecular Medicine, vol. 18, no. 1, pp. 59-68, 2012.

[136] P. Jiao, J. Ma, B. Feng et al., "FFA-induced adipocyte inflammation and insulin resistance: involvement of ER stress and IKK $\beta$ pathways," Obesity, vol. 19, no. 3, pp. 483-491, 2011.

[137] P. Hu, Z. Han, A. D. Couvillon, R. J. Kaufman, and J. H. Exton, "Autocrine tumor necrosis factor alpha links endoplasmic reticulum stress to the membrane death receptor pathway through IRE1 $\alpha$-mediated NF- $\kappa$ B activation and down-regulation of TRAF2 expression," Molecular and Cellular Biology, vol. 26, no. 8, pp. 3071-3084, 2006.

[138] P. S. Gargalovic, N. M. Gharavi, M. J. Clark, J. Pagnon, W. P. Yang, A. He et al., "The unfolded protein response is an important regulator of inflammatory genes in endothelial cells," Arteriosclerosis, Thrombosis, and Vascular Biology, vol. 26, no. 11, pp. 2490-2496, 2006.

[139] S. Braun, K. Bitton-Worms, and D. LeRoith, "The link between the metabolic syndrome and cancer," International Journal of Biological Sciences, vol. 7, no. 7, pp. 1003-1015, 2011.

[140] M. H. Faulds and K. Dahlman-Wright, "Metabolic diseases and cancer risk," Current Opinion in Oncology, vol. 24, no. 1, pp. 5861, 2012. 
[141] I. Vucenik and J. P. Stains, "Obesity and cancer risk: evidence, mechanisms, and recommendations," Annals of the New York Academy of Sciences, vol. 1271, pp. 37-43, 2012.

[142] O. Kaidar-Person, G. Bar-Sela, and B. Person, "The two major epidemics of the twenty-first century: obesity and cancer," Obesity Surgery, vol. 21, no. 11, pp. 1792-1797, 2011.

[143] N. Parekh, U. Chandran, and E. V. Bandera, "Obesity in cancer survival," Annual Review of Nutrition, vol. 32, pp. 311-342, 2012.

[144] E. E. Calle, C. Rodriguez, K. Walker-Thurmond, and M. J. Thun, "Overweight, obesity, and mortality from cancer in a prospectively studied cohort of U.S. Adults," The New England Journal of Medicine, vol. 348, no. 17, pp. 1625-1638, 2003.

[145] E. E. Calle and M. J. Thun, "Obesity and cancer," Oncogene, vol. 23, no. 38, pp. 6365-6378, 2004.

[146] E. E. Calle and R. Kaaks, "Overweight, obesity and cancer: epidemiological evidence and proposed mechanisms," Nature Reviews Cancer, vol. 4, no. 8, pp. 579-591, 2004.

[147] A. G. Renehan, M. Tyson, M. Egger, R. F. Heller, and M. Zwahlen, "Body-mass index and incidence of cancer: a systematic review and meta-analysis of prospective observational studies," The Lancet, vol. 371, no. 9612, pp. 569-578, 2008.

[148] A. G. Renehan, "Bariatric surgery, weight reduction, and cancer prevention," The Lancet Oncology, vol. 10, no. 7, pp. 640-641, 2009.

[149] L. Sjöström, A. Gummesson, C. D. Sjöström et al., "Effects of bariatric surgery on cancer incidence in obese patients in Sweden (Swedish Obese Subjects Study): a prospective, controlled intervention trial," The Lancet Oncology, vol. 10, no. 7, pp. 653-662, 2009.

[150] D. L. Roberts, C. Dive, and A. G. Renehan, "Biological mechanisms linking obesity and cancer risk: new perspectives," Annual Review of Medicine, vol. 61, pp. 301-316, 2010.

[151] E. A. Rondini, A. E. Harvey, J. P. Steibel, S. D. Hursting, and J. I. Fenton, "Energy balance modulates colon tumor growth: interactive roles of insulin and estrogen," Molecular Carcinogenesis, vol. 50, no. 5, pp. 370-382, 2011.

[152] S. D. Hursting and N. A. Berger, "Energy balance, host-related factors, and cancer progression," Journal of Clinical Oncology, vol. 28, no. 26, pp. 4058-4065, 2010.

[153] S. Margetic, C. Gazzola, G. G. Pegg, and R. A. Hill, "Leptin: a review of its peripheral actions and interactions," International Journal of Obesity and Related Metabolic Disorders, vol. 26, no. 11, pp. 1407-1433, 2002.

[154] J. Park and P. E. Scherer, "Leptin and cancer: from cancer stem cells to metastasis," Endocrine-Related Cancer, vol. 18, no. 4, pp. C25-C29, 2011.

[155] J. M. Friedman, "Leptin at 14 y of age: an ongoing story," American Journal of Clinical Nutrition, vol. 89, no. 3, 2009.

[156] M. Maffei, H. Fei, G. H. Lee et al., "Increased expression in adipocytes of ob RNA in mice with lesions of the hypothalamus and with mutations at the db locus," Proceedings of the National Academy of Sciences of the United States of America, vol. 92, no. 15, pp. 6957-6960, 1995.

[157] C. Garofalo and E. Surmacz, "Leptin and cancer," Journal of Cellular Physiology, vol. 207, no. 1, pp. 12-22, 2006.

[158] S. C. Benoit, D. J. Clegg, R. J. Seeley, and S. C. Woods, "Insulin and leptin as adiposity signals," Recent Progress in Hormone Research, vol. 59, pp. 267-285, 2004.

[159] L. Gautron and J. K. Elmquist, "Sixteen years and counting: an update on leptin in energy balance," Journal of Clinical Investigation, vol. 121, no. 6, pp. 2087-2093, 2011.
[160] J. E. Drew, "Molecular mechanisms linking adipokines to obesity-related colon cancer: focus on leptin," Proceedings of the Nutrition Society, vol. 71, no. 1, pp. 175-180, 2012.

[161] Q. Zheng, S. M. Dunlap, J. Zhu, E. Downs-Kelly, J. Rich, S. D. Hursting et al., "Leptin deficiency suppresses MMTV-Wnt1 mammary tumor growth in obese mice and abrogates tumor initiating cell survival," Endocrine-Related Cancer, vol. 18, no. 4, pp. 491-503, 2011.

[162] E. C. Villanueva and M. G. Myers, "Leptin receptor signaling and the regulation of mammalian physiology," International Journal of Obesity, vol. 32, no. 7, pp. S8-S12, 2008.

[163] J. Chen, "Multiple signal pathways in obesity-associated cancer," Obesity Reviews, vol. 12, no. 12, pp. 1063-1070, 2011.

[164] J. Gao, J. Tian, Y. Lv et al., "Leptin induces functional activation of cyclooxygenase-2 through JAK2/ STAT3, MAPK/ERK, and PI3K/AKT pathways in human endometrial cancer cells," Cancer Science, vol. 100, no. 3, pp. 389-395, 2009.

[165] T. Jaffe and B. Schwartz, "Leptin promotes motility and invasiveness in human colon cancer cells by activating multiple signaltransduction pathways," International Journal of Cancer, vol. 123, no. 11, pp. 2543-2556, 2008.

[166] D. L. Morris and L. Rui, "Recent advances in understanding leptin signaling and leptin resistance," American Journal of Physiology, vol. 297, no. 6, pp. E1247-E1259, 2009.

[167] M. Ishikawa, J. Kitayama, and H. Nagawa, "Enhanced expression of leptin and leptin receptor (OB-R) in human breast cancer," Clinical Cancer Research, vol. 10, no. 13, pp. 4325-4331, 2004.

[168] C. Garofalo, M. Koda, S. Cascio et al., "Increased expression of leptin and the leptin receptor as a marker of breast cancer progression: possible role of obesity-related stimuli," Clinical Cancer Research, vol. 12, no. 5, pp. 1447-1453, 2006.

[169] J. M. Howard, P. Beddy, D. Ennis, M. Keogan, G. P. Pidgeon, and J. V. Reynolds, "Associations between leptin and adiponectin receptor upregulation, visceral obesity and tumour stage in oesophageal and junctional adenocarcinoma," British Journal of Surgery, vol. 97, no. 7, pp. 1020-1027, 2010.

[170] J. M. Howard, G. P. Pidgeon, and J. V. Reynolds, "Leptin and gastro-intestinal malignancies," Obesity Reviews, vol. 11, no. 12, pp. 863-874, 2010.

[171] L. Vona-Davis and D. P. Rose, "Adipokines as endocrine, paracrine, and autocrine factors in breast cancer risk and progression," Endocrine-Related Cancer, vol. 14, no. 2, pp. 189206, 2007.

[172] G. A. Bray, "The underlying basis for obesity: relationship to cancer," Journal of Nutrition, vol. 132, no. 11 Supplement, pp. 3451S-3455S, 2002.

[173] D. P. Rose, D. Komninou, and G. D. Stephenson, "Obesity, adipocytokines, and insulin resistance in breast cancer," Obesity Reviews, vol. 5, no. 3, pp. 153-165, 2004.

[174] A. Stofkova, "Leptin and adiponectin: from energy and metabolic dysbalance to inflammation and autoimmunity," Endocrine Regulations, vol. 43, no. 4, pp. 157-168, 2009.

[175] P. E. Scherer, S. Williams, M. Fogliano, G. Baldini, and H. F. Lodish, "A novel serum protein similar to Clq, produced exclusively in adipocytes," Journal of Biological Chemistry, vol. 270, no. 45, pp. 26746-26749, 1995.

[176] T. Yamauchi, J. Kamon, Y. Minokoshi et al., "Adiponectin stimulates glucose utilization and fatty-acid oxidation by activating AMP-activated protein kinase," Nature Medicine, vol. 8, no. 11, pp. 1288-1295, 2002. 
[177] I. Kelesidis, T. Kelesidis, and C. S. Mantzoros, "Adiponectin and cancer: a systematic review," British Journal of Cancer, vol. 94, no. 9, pp. 1221-1225, 2006.

[178] D. Barb, C. J. Williams, A. K. Neuwirth, and C. S. Mantzoros, "Adiponectin in relation to malignancies: a review of existing basic research and clinical evidence," The American Journal of Clinical Nutrition, vol. 86, no. 3, pp. s858-s866, 2007.

[179] U. B. Pajvani, M. Hawkins, T. P. Combs et al., "Complex distribution, not absolute amount of adiponectin, correlates with thiazolidinedione-mediated improvement in insulin sensitivity," Journal of Biological Chemistry, vol. 279, no. 13, pp. 1215212162, 2004.

[180] A. Koerner, J. Kratzsch, and W. Kiess, "Adipocytokines: leptinthe classical, resistin-the controversical, adiponectin-the promising, and more to come," Best Practice and Research, vol. 19, no. 4, pp. 525-546, 2005.

[181] O. Ukkola and M. Santaniemi, "Adiponectin: a link between excess adiposity and associated comorbidities?" Journal of Molecular Medicine, vol. 80, no. 11, pp. 696-702, 2002.

[182] A. Coppola, R. Marfella, L. Coppola et al., "Effect of weight loss on coronary circulation and adiponectin levels in obese women," International Journal of Cardiology, vol. 134, no. 3, pp. 414-416, 2009.

[183] T. Yamauchi, J. Kamon, H. Waki et al., "The fat-derived hormone adiponectin reverses insulin resistance associated with both lipoatrophy and obesity," Nature Medicine, vol. 7, no. 8, pp. 941-946, 2001.

[184] J. Bełtowski, "Adiponectin and resistin-new hormones of white adipose tissue," Medical Science Monitor, vol. 9, no. 2, pp. RA55-RA61, 2003.

[185] M. Dalamaga, K. N. Diakopoulos, and C. S. Mantzoros, "The role of adiponectin in cancer: a review of current evidence," Endocrine Reviews, vol. 33, no. 4, pp. 547-594, 2012.

[186] V. Izadi, E. Farabad, and L. Azadbakht, "Serum adiponectin level and different kinds of cancer: a review of recent evidence," ISRN Oncology, vol. 2012, Article ID 982769, 2012.

[187] A. M. Kucharska-Newton, W. D. Rosamond, P. J. Mink, A. J. Alberg, E. Shahar, and A. R. Folsom, "HDL-cholesterol and incidence of breast cancer in the ARIC Cohort Study," Annals of Epidemiology, vol. 18, no. 9, pp. 671-677, 2008.

[188] A. S. Furberg, M. B. Veierød, T. Wilsgaard, L. Berstein, and I. Thune, "Serum high density lipoprotein cholesterol, metabolic profile, and breast cancer risk," Journal of the National Cancer Institute, vol. 96, no. 15, pp. 1152-1160, 2004.

[189] A. S. Furberg, G. Jasienska, N. Bjurstam et al., "Metabolic and hormonal profiles: HDL cholesterol as a plausible biomarker of breast cancer risk. The Norwegian EBBA study," Cancer Epidemiology Biomarkers and Prevention, vol. 14, no. 1, pp. 3340, 2005.

[190] U. Lim, T. Gayles, H. A. Katki et al., "Serum high-density lipoprotein cholesterol and risk of non-hodgkin lymphoma," Cancer Research, vol. 67, no. 11, pp. 5569-5574, 2007.

[191] L. Magura, R. Blanchard, B. Hope, J. R. Beal, G. G. Schwartz, and A. E. Sahmoun, "Hypercholesterolemia and prostate cancer: a hospital-based case-control study," Cancer Causes and Control, vol. 19, no. 10, pp. 1259-1266, 2008.

[192] J. Manjer, G. Berglund, L. Bondesson et al., "Intra-urban differences in breast cancer mortality: a study from the city of Malmo in Sweden," Journal of Epidemiology and Community Health, vol. 54, no. 4, pp. 279-285, 2000.
[193] V. G. Kaklamani, M. Sadim, A. Hsi et al., "Variants of the adiponectin and adiponectin receptor 1 genes and breast cancer risk," Cancer Research, vol. 68, no. 9, pp. 3178-3184, 2008.

[194] A. Korner, K. Pazaitou-Panayiotou, T. Kelesidis, I. Kelesidis, C. J. Williams, A. Kaprara et al., "Total and high-molecular-weight adiponectin in breast cancer: in vitro and in vivo studies," Journal of Clinical Endocrinology and Metabolism, vol. 92, no. 3, pp. 1041-1048, 2007.

[195] C. Mantzoros, E. Petridou, N. Dessypris, C. Chavelas, M. Dalamaga, D. M. Alexe et al., "Adiponectin and breast cancer risk," Journal of Clinical Endocrinology and Metabolism, vol. 89, no. 3, pp. 1102-1107, 2004.

[196] K. Michalakis, C. J. Williams, N. Mitsiades et al., "Serum adiponectin concentrations and tissue expression of adiponectin receptors are reduced in patients with prostate cancer: a case control study," Cancer Epidemiology Biomarkers and Prevention, vol. 16, no. 2, pp. 308-313, 2007.

[197] S. Otake, H. Takeda, S. Fujishima et al., "Decreased levels of plasma adiponectin associated with increased risk of colorectal cancer," World Journal of Gastroenterology, vol. 16, no. 10, pp. 1252-1257, 2010.

[198] B. He, Y. Pan, Y. Zhang et al., "Effects of genetic variations in the Adiponectin pathway genes on the risk of colorectal cancer in the Chinese population," BMC Medical Genetics, vol. 12, article 94, 2011.

[199] A. Yildirim, M. Bilici, K. Çayir, V. Yanmaz, S. Yildirim, and S. B. Tekin, "Serum adiponectin levels in patients with esophageal cancer," Japanese Journal of Clinical Oncology, vol. 39, no. 2, pp. 92-96, 2009.

[200] R. Z. Stolzenberg-Solomon, S. Weinstein, M. Pollak et al., "Prediagnostic adiponectin concentrations and pancreatic cancer risk in male smokers," American Journal of Epidemiology, vol. 168, no. 9, pp. 1047-1055, 2008.

[201] S. D. Hursting, L. M. Lashinger, K. W. Wheatley et al., "Reducing the weight of cancer: mechanistic targets for breaking the obesity-carcinogenesis link," Best Practice \& Research, vol. 22, no. 4, pp. 659-669, 2008.

[202] R. Kaaks, A. Lukanova, and M. S. Kurzer, "Obesity, endogenous hormones, and endometrial cancer risk: a synthetic review," Cancer Epidemiology Biomarkers and Prevention, vol. 11, no. 12, pp. 1531-1543, 2002.

[203] T. J. Key and V. G. Vogel, "Body mass index, serum sex hormones, and breast cancer risk in postmenopausal women," Breast Diseases, vol. 95, no. 16, pp. 1218-1226, 2003.

[204] R. Kaaks, S. Rinaldi, T. J. Key et al., "Postmenopausal serum androgens, oestrogens and breast cancer risk: the European prospective investigation into cancer and nutrition," EndocrineRelated Cancer, vol. 12, no. 4, pp. 1071-1082, 2005.

[205] C. A. Derby, S. Zilber, D. Brambilla, K. H. Morales, and J. B. McKinlay, "Body mass index, waist circumference and waist to hip ratio and change in sex steroid hormones: the Massachusetts Male Ageing Study," Clinical Endocrinology, vol. 65, no. 1, pp. 125-131, 2006.

[206] K. Nanda, L. A. Bastian, V. Hasselblad, and D. L. Simel, "Hormone replacement therapy and the risk of colorectal cancer: a meta- analysis," Obstetrics and Gynecology, vol. 93, no. 5, pp. 880-888, 1999.

[207] H. D. Nelson, L. L. Humphrey, P. Nygren, S. M. Teutsch, and J. D. Allan, "Postmenopausal hormone replacement therapy: scientific review," Journal of the American Medical Association, vol. 288 , no. 7, pp. 872-881, 2002. 
[208] M. L. Slattery, C. Sweeney, M. Murtaugh, K. N. Ma, R. K. Wolff et al., "Associations between ERalpha, ERbeta, and AR genotypes and colon and rectal cancer," Cancer Epidemiology, Biomarkers \& Prevention, vol. 14, no. 12, pp. 2936-2942, 2005.

[209] R. H. Straub, "The complex role of estrogens in inflammation," Endocrine Reviews, vol. 28, no. 5, pp. 521-574, 2007.

[210] X. P. Jiang, D. C. Yang, R. L. Elliott, and J. F. Head, "Reduction in serum IL-6 after vacination of breast cancer patients with tumour-associated antigens is related to estrogen receptor status," Cytokine, vol. 12, no. 5, pp. 458-465, 2000.

[211] J. E. Morley and R. N. Baumgartner, "Cytokine-related aging process," Journals of Gerontology Series A, vol. 59, no. 9, pp. M924-M929, 2004.

[212] W. J. Loh, B. V. North, D. G. Johnston, and I. F. Godsland, "Insulin resistance-related biomarker clustering and subclinical inflammation as predictors of cancer mortality during 21.5 years of follow-up," Cancer Causes and Control, vol. 21, no. 5, pp. 709718, 2010.

[213] B. B. Kahn and J. S. Flier, "Obesity and insulin resistance," Journal of Clinical Investigation, vol. 106, no. 4, pp. 473-481, 2000.

[214] P. Pisani, "Hyper-insulinaemia and cancer, meta-analyses of epidemiological studies," Archives of Physiology and Biochemistry, vol. 114, no. 1, pp. 63-70, 2008.

[215] I. M. Jazet, H. Pijl, and A. E. Meinders, "Adipose tissue as an endocrine organ: impact on insulin resistance," Netherlands Journal of Medicine, vol. 61, no. 6, pp. 194-212, 2003.

[216] S. E. Kahn, R. L. Hull, and K. M. Utzschneider, "Mechanisms linking obesity to insulin resistance and type 2 diabetes," Nature, vol. 444, no. 7121, pp. 840-846, 2006.

[217] S. E. Shoelson, J. Lee, and A. B. Goldfine, "Inflammation and insulin resistance," Journal of Clinical Investigation, vol. 116, no. 7, pp. 1793-1801, 2006.

[218] M. Gautam, T. M. DeChiara, D. J. Glass, G. D. Yancopoulos, and J. R. Sanes, "Distinct phenotypes of mutant mice lacking agrin, MuSK, or rapsyn," Developmental Brain Research, vol. 114, no. 2, pp. 171-178, 1999.

[219] M. Pollak, "Insulin, insulin-like growth factors and neoplasia," Best Practice and Research, vol. 22, no. 4, pp. 625-638, 2008.

[220] J. Dupont and D. Le Roith, "Insulin-like growth factor 1 and oestradiol promote cell proliferation of MCF-7 breast cancer cells: new insights into their synergistic effects," Journal of Clinical Pathology, vol. 54, no. 3, pp. 149-154, 2001.

[221] A. A. Samani, S. Yakar, D. LeRoith, and P. Brodt, "The role of the IGF system in cancer growth and metastasis: overview and recent insights," Endocrine Reviews, vol. 28, no. 1, pp. 20-47, 2007.

[222] R. Kooijman, "Regulation of apoptosis by insulin-like growth factor (IGF)-I," Cytokine and Growth Factor Reviews, vol. 17, no. 4, pp. 305-323, 2006.

[223] J. Frystyk, "Free insulin-like growth factors-measurements and relationships to growth hormone secretion and glucose homeostasis," Growth Hormone and IGF Research, vol. 14, no. 5, pp. 337-375, 2004.

[224] S. D. Hursting, S. M. Smith, L. M. Lashinger, A. E. Harvey, and S. N. Perkins, "Calories and carcinogenesis: lessons learned from 30 years of calorie restriction research," Carcinogenesis, vol. 31, no. 1, Article ID bgp280, pp. 83-89, 2009.

[225] A. G. Renehan, J. Frystyk, and A. Flyvbjerg, "Obesity and cancer risk: the role of the insulin-IGF axis," Trends in Endocrinology and Metabolism, vol. 17, no. 8, pp. 328-336, 2006.
[226] R. Huxley, A. Ansary-Moghaddam, A. Berrington De González, F. Barzi, and M. Woodward, "Type-II diabetes and pancreatic cancer: a meta-analysis of 36 studies," British Journal of Cancer, vol. 92, no. 11, pp. 2076-2083, 2005.

[227] P. Lindblad, W. H. Chow, J. Chan et al., "The role of diabetes mellitus in the aetiology of renal cell cancer," Diabetologia, vol. 42, no. 1, pp. 107-112, 1999.

[228] E. Friberg, C. S. Mantzoros, and A. Wolk, "Diabetes and risk of endometrial cancer: a population-based prospective cohort study," Cancer Epidemiology Biomarkers and Prevention, vol. 16, no. 2, pp. 276-280, 2007.

[229] R. Kaaks, "Nutrition, hormones, and breast cancer: is insulin the missing link?" Cancer Causes and Control, vol. 7, no. 6, pp. 605-625, 1996.

[230] A. G. Renehan, D. L. Roberts, and C. Dive, "Obesity and cancer: pathophysiological and biological mechanisms," Archives of Physiology and Biochemistry, vol. 114, no. 1, pp. 71-83, 2008.

[231] A. Wolk, C. S. Mantzoros, S. O. Andersson et al., "Insulin-like growth factor 1 and prostate cancer risk: a population- based, case-control study," Journal of the National Cancer Institute, vol. 90, no. 12, pp. 911-915, 1998.

[232] C. W. M. Cutting, C. Hunt, J. A. Nisbet, J. M. Bland, A. G. Dalgleish, and R. S. Kirby, "Serum insulin-like growth factor1 is not a useful marker of prostate cancer," BJU International, vol. 83, no. 9, pp. 996-999, 1999.

[233] S. E. Hankinson, W. C. Willett, G. A. Colditz et al., "Circulating concentrations of insulin-like growth factor-I and risk of breast cancer," The Lancet, vol. 351, no. 9113, pp. 1393-1396, 1998.

[234] N. K. Saxena, L. Taliaferro-Smith, B. B. Knight et al., "Bidirectional crosstalk between leptin and insulin-like growth factor-I signaling promotes invasion and migration of breast cancer cells via transactivation of epidermal growth factor receptor," Cancer Research, vol. 68, no. 23, pp. 9712-9722, 2008.

[235] J. Nakae, Y. Kido, and D. Accili, "Distinct and overlapping functions of insulin and IGF-I receptors," Endocrine Reviews, vol. 22, no. 6, pp. 818-835, 2001.

[236] E. J. Gallagher and D. LeRoith, "The proliferating role of insulin and insulin-like growth factors in cancer," Trends in Endocrinology and Metabolism, vol. 21, no. 10, pp. 610-618, 2010.

[237] L. W. Ellisen, "Growth control under stress: mTOR regulation through the REDD1-TSC pathway," Cell Cycle, vol. 4, no. 11, pp. 1500-1502, 2005.

[238] J. Brugarolas, K. Lei, R. L. Hurley et al., "Regulation of mTOR function in response to hypoxia by REDD1 and the TSC1/TSC2 tumor suppressor complex," Genes and Development, vol. 18, no. 23, pp. 2893-2904, 2004.

[239] C. M. Perks, E. G. Vernon, A. H. Rosendahl, D. Tonge, and J. M. Holly, "IGF-II and IGFBP-2 differentially regulate PTEN in human breast cancer cells," Oncogene, vol. 26, no. 40, pp. 59665972, 2007.

[240] A. V. Lee, J. G. Jackson, J. L. Gooch et al., "Enhancement of insulin-like growth factor signaling in human breast cancer: estrogen regulation of insulin receptor substrate-1 expression in vitro and in vivo," Molecular Endocrinology, vol. 13, no. 5, pp. 787-796, 1999.

[241] M. Gallí, F. Van Gool, and O. Leo, "Sirtuins and inflammation: friends or foes?” Biochemical Pharmacology, vol. 81, no. 5, pp. 569-576, 2011.

[242] H. Y. Cohen, C. Miller, K. J. Bitterman et al., "Calorie restriction promotes mammalian cell survival by inducing the SIRT1 deacetylase," Science, vol. 305, no. 5682, pp. 390-392, 2004. 
[243] L. Qiang, H. Wang, and S. R. Farmer, "Adiponectin secretion is regulated by SIRT1 and the endoplasmic reticulum oxidoreductase Erol-L $\alpha$," Molecular and Cellular Biology, vol. 27, no. 13, pp. 4698-4707, 2007.

[244] L. Qiao and J. Shao, "SIRT1 regulates adiponectin gene expression through Foxol-C/enhancer- binding protein $\alpha$ transcriptional complex," Journal of Biological Chemistry, vol. 281, no. 52, pp. 39915-39924, 2006.

[245] L. Bordone, D. Cohen, A. Robinson et al., "SIRT1 transgenic mice show phenotypes resembling calorie restriction," Aging Cell, vol. 6, no. 6, pp. 759-767, 2007.

[246] K. M. Ramsey, K. F. Mills, A. Satoh, and S. I. Imai, "Age-associated loss of Sirtl-mediated enhancement of glucose-stimulated insulin secretion in beta cell-specific Sirtl-overexpressing (BESTO) mice," Aging Cell, vol. 7, no. 1, pp. 78-88, 2008.

[247] S. Nemoto, M. M. Fergusson, and T. Finkel, "SIRT1 functionally interacts with the metabolic regulator and transcriptional coactivator PGC-1 $\alpha$," Journal of Biological Chemistry, vol. 280, no. 16, pp. 16456-16460, 2005.

[248] E. Nisoli, C. Tonello, A. Cardile et al., "Cell biology: calorie restriction promotes mitochondrial biogenesis by inducing the expression of eNOS," Science, vol. 310, no. 5746, pp. 314-317, 2005.

[249] C. S. Lim, "SIRT1: tumor promoter or tumor suppressor?" Medical Hypotheses, vol. 67, no. 2, pp. 341-344, 2006.

[250] J. Ford, M. Jiang, and J. Milner, "Cancer-specific functions of SIRT1 enable human epithelial cancer cell growth and survival," Cancer Research, vol. 65, no. 22, pp. 10457-10463, 2005.

[251] J. A. Baur and D. A. Sinclair, "Therapeutic potential of resveratrol: the in vivo evidence," Nature Reviews Drug Discovery, vol. 5, no. 6, pp. 493-506, 2006.

[252] D. McGuinness, D. H. McGuinness, J. A. McCaul, P. G. Shiels et al., "Sirtuins, bioageing, and cancer," Journal of Aging Research, vol. 2011, Article ID 235754, 11 pages, 2011.

[253] P. Trayhurn, B. Wang, and I. S. Wood, "Hypoxia in adipose tissue: a basis for the dysregulation of tissue function in obesity?" British Journal of Nutrition, vol. 100, no. 2, pp. 227235, 2008.

[254] G. L. Semenza, "Targeting HIF-1 for cancer therapy," Nature Reviews Cancer, vol. 3, no. 10, pp. 721-732, 2003.

[255] P. Vaupel and M. Hoeckel, "Predictive power of the tumor oxygenation status," Advances in Experimental Medicine and Biology, vol. 471, pp. 533-539, 2000.

[256] H. K. Eltzschig and P. Carmeliet, "Hypoxia and inflammation," The New England Journal of Medicine, vol. 364, no. 7, pp. 656665, 2011.

[257] R. Cancello, C. Henegar, N. Viguerie et al., "Reduction of macrophage infiltration and chemoattractant gene expression changes in white adipose tissue of morbidly obese subjects after surgery-induced weight loss," Diabetes, vol. 54, no. 8, pp. 22772286, 2005.

[258] Y. Higami, J. L. Barger, G. P. Page et al., "Energy restriction lowers the expression of genes linked to inflammation, the cytoskeleton, the extracellular matrix, and angiogenesis in mouse adipose tissue," Journal of Nutrition, vol. 136, no. 2, pp. 343-352, 2006.

[259] M. Hofker and C. Wijmenga, "A supersized list of obesity genes," Nature Genetics, vol. 41, no. 2, pp. 139-140, 2009.

[260] P. D. P. Pharoah, A. C. Antoniou, D. F. Easton, and B. A. J. Ponder, "Polygenes, risk prediction, and targeted prevention of breast cancer," The New England Journal of Medicine, vol. 358, no. 26, pp. 2796-2803, 2008.
[261] S. Ahmed, G. Thomas, M. Ghoussaini, C. S. Healey, M. K. Humphreys, R. Platte et al., "Newly discovered breast cancer susceptibility loci on 3p24 and 17q23," Nature Genetics, vol. 41, no. 5, pp. 585-590, 2009.

[262] A. Tenesa and M. G. Dunlop, "New insights into the aetiology of colorectal cancer from genome-wide association studies," Nature Reviews Genetics, vol. 10, no. 6, pp. 353-358, 2009.

[263] A. Tenesa, H. Campbell, E. Theodoratou et al., "Common genetic variants at the MC4R locus are associated with obesity, but not with dietary energy intake or colorectal cancer in the Scottish population," International Journal of Obesity, vol. 33, no. 2, pp. 284-288, 2009.

[264] M. S. Rodeheffer, K. Birsoy, and J. M. Friedman, "Identification of white adipocyte progenitor cells in vivo," Cell, vol. 135, no. 2, pp. 240-249, 2008.

[265] A. H. Klopp, Y. Zhang, T. Solley, F. Amaya-Manzanares, F. Marini, M. Andreeff et al., "Omental adipose tissue-derived stromal cells promote vascularization and growth of endometrial tumors," Clinical Cancer Research, vol. 18, no. 3, pp. 771782, 2012.

[266] Y. Zhang, A. C. Daquinag, F. Amaya-Manzanares, O. Sirin, C. Tseng, and M. G. Kolonin, "Stromal progenitor cells from endogenous adipose tissue contribute to pericytes and adipocytes that populate the tumor microenvironment," Cancer Research, vol. 72, no. 20, pp. 5198-5208, 2012.

[267] S. Schenk, M. Saberi, and J. M. Olefsky, "Insulin sensitivity: modulation by nutrients and inflammation," Journal of Clinical Investigation, vol. 118, no. 9, pp. 2992-3002, 2008.

[268] C. de Luca and J. M. Olefsky, "Inflammation and insulin resistance," FEBS Letters, vol. 582, no. 1, pp. 97-105, 2008.

[269] S. E. Kahn, B. Zinman, S. M. Haffner et al., "Obesity is a major determinant of the association of C-reactive protein levels and the metabolic syndrome in type 2 diabetes," Diabetes, vol. 55 , no. 8, pp. 2357-2364, 2006.

[270] G. S. Hotamisligil, N. S. Shargill, and B. M. Spiegelman, "Adipose expression of tumor necrosis factor- $\alpha$ : direct role in obesity-linked insulin resistance," Science, vol. 259, no. 5091, pp. 87-91, 1993.

[271] C. S. Kim, H. S. Park, T. Kawada et al., "Circulating levels of MCP-1 and IL- 8 are elevated in human obese subjects and associated with obesity-related parameters," International Journal of Obesity, vol. 30, no. 9, pp. 1347-1355, 2006.

[272] N. B. Ruderman, S. H. Schneider, and P. Berchtold, "The "metabolically-obese," normal-weight individual," American Journal of Clinical Nutrition, vol. 34, no. 8, pp. 1617-1621, 1981.

[273] R. P. Wildman, P. Muntner, K. Reynolds et al., "The obese without cardiometabolic risk factor clustering and the normal weight with cardiometabolic risk factor clustering: prevalence and correlates of 2 phenotypes among the US population (NHANES 1999-2004)," Archives of Internal Medicine, vol. 168, no. 15, pp. 1617-1624, 2008.

[274] E. Succurro, M. A. Marini, S. Frontoni et al., "Insulin secretion in metabolically obese, but normal weight, and in metabolically healthy but obese individuals," Obesity, vol. 16, no. 8, pp. 1881$1886,2008$.

[275] F. Wang, H. Liu, W. P. Blanton, A. Belkina, N. K. Lebrasseur, and G. V. Denis, "Brd2 disruption in mice causes severe obesity without Type 2 diabetes," Biochemical Journal, vol. 425, no. 1, pp. 71-83, 2010.

[276] A. C. Belkina and G. V. Denis, "Obesity genes and insulin resistance," Current Opinion in Endocrinology, Diabetes and Obesity, vol. 17, no. 5, pp. 472-477, 2010. 
[277] G. Sethi, M. K. Shanmugam, L. Ramachandran, A. P. Kumar, and V. Tergaonkar, "Multifaceted link between cancer and inflammation," Bioscience Reports, vol. 32, no. 1, pp. 1-15, 2012.

[278] M. Visser, L. M. Bouter, G. M. McQuillan, M. H. Wener, and T. B. Harris, "Elevated C-reactive protein levels in overweight and obese adults," Journal of the American Medical Association, vol. 282, no. 22, pp. 2131-2135, 1999.

[279] D. C. W. Lau, B. Dhillon, H. Yan, P. E. Szmitko, and S. Verma, "Adipokines: molecular links between obesity and atheroslcerosis," American Journal of Physiology, vol. 288, no. 5, pp. H2031H2041, 2005.

[280] A. Festa, R. D’Agostino, R. P. Tracy, and S. M. Haffner, "Elevated levels of acute-phase proteins and plasminogen activator inhibitor-1 predict the development of type 2 diabetes: the insulin resistance atherosclerosis study," Diabetes, vol. 51, no. 4, pp. 1131-1137, 2002.

[281] D. J. Freeman, J. Norrie, M. J. Caslake et al., "C-reactive protein is an independent predictor of risk for the development of diabetes in the west of Scotland coronary prevention study," Diabetes, vol. 51, no. 5, pp. 1596-1600, 2002.

[282] T. P. Erlinger, E. A. Platz, N. Rifai, and K. J. Helzlsouer, "Creactive protein and the risk of incident colorectal cancer," Journal of the American Medical Association, vol. 291, no. 5, pp. 585-590, 2004.

[283] E. Volkova, J. A. Willis, J. E. Wells, B. A. Robinson, G. U. Dachs, and M. J. Currie, "Association of angiopoietin-2, Creactive protein and markers of obesity and insulin resistance with survival outcome in colorectal cancer," British Journal of Cancer, vol. 104, no. 1, pp. 51-59, 2011.

[284] J. H. Kim, R. A. Bachmann, and J. Chen, "Interleukin-6 and insulin resistance," Vitamins \& Hormones, vol. 80, pp. 613-633, 2009.

[285] H. S. Park, J. Y. Park, and R. Yu, "Relationship of obesity and visceral adiposity with serum concentrations of CRP, TNF- $\alpha$ and IL-6," Diabetes Research and Clinical Practice, vol. 69, no. 1, pp. 29-35, 2005.

[286] V. Syed, G. Ulinski, S. C. Mok, and S. M. Ho, "Reproductive hormone-induced, STAT3-mediated interleukin 6 action in normal and malignant human ovarian surface epithelial cells," Journal of the National Cancer Institute, vol. 94, no. 8, pp. 617629, 2002.

[287] V. Sriuranpong, J. I. Park, P. Amornphimoltham, V. Patel, B. D. Nelkin, and J. S. Gutkind, "Epidermal growth factor receptor-independent constitutive activation of STAT3 in head and neck squamous cell carcinoma is mediated by the autocrine/paracrine stimulation of the interleukin 6/gp130 cytokine system," Cancer Research, vol. 63, no. 11, pp. 29482956, 2003.

[288] D. Giri, M. Ozen, and M. Ittmann, "Interleukin-6 is an autocrine growth factor in human prostate cancer," American Journal of Pathology, vol. 159, no. 6, pp. 2159-2165, 2001.

[289] Y. Y. Li, L. L. Hsieh, R. P. Tang, S. K. Liao, and K. Y. Yeh, "Interleukin-6 (IL-6) released by macrophages induces IL-6 secretion in the human colon cancer HT-29 cell line," Human Immunology, vol. 70, no. 3, pp. 151-158, 2009.

[290] T. Yokoe, Y. Iino, H. Takei et al., "Changes of cytokines and thyroid function in patients with recurrent breast cancer," Anticancer Research, vol. 17, no. 1 B, pp. 695-699, 1997.

[291] J. S. Goydos, A. M. Brumfield, E. Frezza, A. Booth, M. T. Lotze, and S. E. Carty, "Marked elevation of serum interleukin6 in patients with cholangiocarcinoma: validation of utility as a clinical marker," Annals of Surgery, vol. 227, no. 3, pp. 398-404, 1998.

[292] H. A. Preti, F. Cabanillas, M. Talpaz, S. L. Tucker, J. F. Seymour, and R. Kurzrock, "Prognostic value of serum interleukin-6 in diffuse large-cell lymphona," Annals of Internal Medicine, vol. 127, no. 3, pp. 186-194, 1997.

[293] A. Dowlati, N. Levitan, and S. C. Remick, "Evaluation of interleukin-6 in bronchoalveolar lavage fluid and serum of patients with lung cancer," Journal of Laboratory and Clinical Medicine, vol. 134, no. 4, pp. 405-409, 1999.

[294] R. Mouawad, A. Benhammouda, O. Rixe et al., "Endogenous interleukin 6 levels in patients with metastatic malignant melanoma: correlation with tumor burden," Clinical Cancer Research, vol. 2, no. 8, pp. 1405-1409, 1996.

[295] A. Wierzbowska, H. Urbanska-Rys, and T. Robak, "Circulating IL-6-type cytokines and sIL-6R in patients with multiple myeloma," British Journal of Haematology, vol. 105, no. 2, pp. 412-419, 1999.

[296] S. Okada, T. Okusaka, H. Ishii, A. Kyogoku, M. Yoshimori, N. Kajimura et al., "Elevated serum interleukin-6 levels in patients with pancreatic cancer," Japanese Journal of Clinical Oncology, vol. 28, no. 1, pp. 12-15, 1998.

[297] J. Nakashima, M. Tachibana, Y. Horiguchi et al., "Serum interleukin 6 as a prognostic factor in patients with prostate cancer," Clinical Cancer Research, vol. 6, no. 7, pp. 2702-2706, 2000.

[298] J. Y. Blay, J. F. Rossi, J. Wijdenes, C. Menetrier-Caux, S. Schemann, S. Négrier et al., "Role of interleukin-6 in the paraneoplastic inflammatory syndrome associated with renal-cell carcinoma," International Journal of Cancer, vol. 72, no. 3, pp. 424-430, 1997.

[299] E. J. Park, J. H. Lee, G. Y. Yu et al., "Dietary and genetic obesity promote liver inflammation and tumorigenesis by enhancing IL-6 and TNF expression," Cell, vol. 140, no. 2, pp. 197-208, 2010.

[300] G. He, G. Y. Yu, V. Temkin, H. Ogata, C. Kuntzen, T. Sakurai et al., "Hepatocyte IKKbeta/NF-kappaB inhibits tumor promotion and progression by preventing oxidative stress-driven STAT3 activation," Cancer Cell, vol. 17, no. 3, pp. 286-297, 2010.

[301] B. Sun and M. Karin, "Obesity, inflammation, and liver cancer," Journal of Hepatology, vol. 56, no. 3, pp. 704-713, 2012.

[302] T. H. Kim, S. E. Choi, E. S. Ha et al., "IL-6 induction of TLR-4 gene expression via STAT3 has an effect on insulin resistance in human skeletal muscle," Acta Diabetologica, vol. 50, no. 2, pp. 189-200, 2013.

[303] J. J. Senn, P. J. Klover, I. A. Nowak, and R. A. Mooney, "Interleukin-6 induces cellular insulin resistance in hepatocytes," Diabetes, vol. 51, no. 12, pp. 3391-3399, 2002.

[304] M. B. Olszewski, A. J. Groot, J. Dastych, and E. F. Knol, "TNF trafficking to human mast cell granules: mature chaindependent endocytosis," Journal of Immunology, vol. 178, no. 9, pp. 5701-5709, 2007.

[305] L. C. Gahring, N. G. Carlson, R. A. Kulmer, and S. W. Rogers, "Neuronal expression of tumor necrosis factor alpha in the murine brain," NeuroImmunoModulation, vol. 3, no. 5, pp. 289303, 1997.

[306] H. Wajant, K. Pfizenmaier, and P. Scheurich, "Tumor necrosis factor signaling," Cell Death and Differentiation, vol. 10, no. 1, pp. 45-65, 2003.

[307] T. Tzanavari, P. Giannogonas, and K. P. Karalis, "TNF- $\alpha$ and obesity," Current Directions in Autoimmunity, vol. 11, pp. 145156, 2010. 
[308] D. F. Jelinek and P. E. Lipsky, "Enhancement of human B cell proliferation and differentiation by tumor necrosis factor- $\alpha$ and interleukin 11," Journal of Immunology, vol. 139, no. 9, pp. 29702976, 1987.

[309] T. Tao, Y. Ji, C. Cheng et al., "Tumor necrosis factor-alpha inhibits Schwann cell proliferation by up-regulating Src-suppressed protein kinase C substrate expression," Journal of Neurochemistry, vol. 111, no. 3, pp. 647-655, 2009.

[310] B. Zinman, A. J. G. Hanley, S. B. Harris, J. Kwan, and I. G. Fantus, "Circulating tumor necrosis factor- $\alpha$ concentrations in a native canadian population with high rates of type 2 diabetes mellitus," Journal of Clinical Endocrinology and Metabolism, vol. 84, no. 1, pp. 272-278, 1999.

[311] K. T. Uysal, S. M. Wiesbrock, M. W. Marino, and G. S. Hotamisligil, "Protection from obesity-induced insulin resistance in mice lacking TNF- $\alpha$ function," Nature, vol. 389, no. 6651, pp. 610-614, 1997.

[312] X. Wang and Y. Lin, "Tumor necrosis factor and cancer, buddies or foes?" Acta Pharmacologica Sinica, vol. 29, no. 11, pp. 12751288, 2008.

[313] M. Pera, C. Manterola, O. Vidal, and L. Grande, "Epidemiology of esophageal adenocarcinoma," Journal of Surgical Oncology, vol. 92, no. 3, pp. 151-159, 2005.

[314] G. K. Reeves, K. Pirie, V. Beral, J. Green, E. Spencer, and D. Bull, "Cancer incidence and mortality in relation to body mass index in the Million Women Study: Cohort study," British Medical Journal, vol. 335, no. 7630, pp. 1134-1139, 2007.

[315] A. Kubo and D. A. Corley, "Body mass index and adenocarcinomas of the esophagus or gastric cardia: a systematic review and meta-analysis," Cancer Epidemiology Biomarkers and Prevention, vol. 15, no. 5, pp. 872-878, 2006.

[316] N. Pandeya, A. C. Green, and D. C. Whiteman, "Australian Cancer Study Prevalence and determinants of frequent gastroesophageal reflux symptoms in the Australian community," Diseases of the Esophagus, vol. 25, no. 7, pp. 573-583, 2012.

[317] R. K. Wood and Y. X. Yang, "Barrett's esophagus in 2008: an update," Keio Journal of Medicine, vol. 57, no. 3, pp. 132-138, 2008.

[318] A. M. Ryan, M. Duong, L. Healy et al., "Obesity, metabolic syndrome and esophageal adenocarcinoma: epidemiology, etiology and new targets," Cancer Epidemiology, vol. 35, no. 4, pp. 309319, 2011.

[319] S. Nair, S. Verma, and P. J. Thuluvath, "Obesity and its effect on survival in patients undergoing orthotopic liver transplantation in the United States," Hepatology, vol. 35, no. 1, pp. 105-109, 2002.

[320] J. M. Regimbeau, M. Columbat, P. Mognol et al., "Obesity and diabetes as a risk factor for hepatocellular carcinoma," Liver Transplantation, vol. 10, no. 2, pp. S69-S73, 2004.

[321] W. H. Chow, G. Gridley, J. F. Fraumeni, and B. Järvholm, "Obesity, hypertension, and the risk of kidney cancer in men," The New England Journal of Medicine, vol. 343, no. 18, pp. 13051311, 2000.

[322] T. Pischon, P. H. Lahmann, H. Boeing et al. et al., "Body size and risk of colon and rectal cancer in the European Prospective Investigation Into Cancer and Nutrition (EPIC)," Journal of the National Cancer Institute, vol. 98, no. 13, pp. 920-931, 2006.

[323] M. Jenab, E. Riboli, R. J. Cleveland et al., "Serum C-peptide, IGFBP-1 and IGFBP-2 and risk of colon and rectal cancers in the European prospective investigation into cancer and nutrition," International Journal of Cancer, vol. 121, no. 2, pp. 368-376, 2007.
[324] M. S. Sandhu, D. B. Dunger, and E. L. Giovannucci, "Insulin, insulin-like growth factor-I (IGF-I), IGF binding proteins, their biologic interactions, and colorectal cancer," Journal of the National Cancer Institute, vol. 94, no. 13, pp. 972-980, 2002.

[325] J. Ma, M. N. Pollak, E. Giovannucci et al., "Prospective study of colorectal cancer risk in men and plasma levels of insulin-like growth factor (IGF)-I and IGF-binding protein-3," Journal of the National Cancer Institute, vol. 91, no. 7, pp. 620-625, 1999.

[326] A. G. Renehan, M. Zwahlen, C. Minder, S. T. O’Dwyer, S. M. Shalet, and M. Egger, "Insulin-like growth factor (IGF)-I, IGF binding protein-3, and cancer risk: systematic review and metaregression analysis," The Lancet, vol. 363, no. 9418, pp. 13461353, 2004.

[327] S. A. Aaronson, "Growth factors and cancer," Science, vol. 254, no. 5035, pp. 1146-1153, 1991.

[328] R. Kaaks and A. Lukanova, "Energy balance and cancer: the role of insulin and insulin-like growth factor-I," Proceedings of the Nutrition Society, vol. 60, no. 1, pp. 91-106, 2001.

[329] P. Stattin, A. Lukanova, C. Biessy et al., "Obesity and colon cancer: does leptin provide a link?” International Journal of Cancer, vol. 109, no. 1, pp. 149-152, 2004.

[330] P. Stattin, R. Palmqvist, S. Söderberg et al., "Plasma leptin and colorectal cancer risk: a prospective study in Northern Sweden," Oncology Reports, vol. 10, no. 6, pp. 2015-2021, 2003.

[331] C. L. Ogden, M. D. Carroll, L. R. Curtin, M. A. McDowell, C. J. Tabak, and K. M. Flegal, "Prevalence of overweight and obesity in the United States, 1999-2004," Journal of the American Medical Association, vol. 295, no. 13, pp. 1549-1555, 2006.

[332] E. K. Wei, E. Giovannucci, C. S. Fuchs, W. C. Willett, and C. S. Mantzoros, "Low plasma adiponectin levels and risk of colorectal cancer in men: a prospective study," Journal of the National Cancer Institute, vol. 97, no. 22, pp. 1688-1694, 2005.

[333] A. Lukanova, S. Söderberg, R. Kaaks, E. Jellum, and P. Stattin, "Serum adiponectin is not associated with risk of colorectal cancer," Cancer Epidemiology Biomarkers and Prevention, vol. 15, no. 2, pp. 401-402, 2006.

[334] D. C. McMillan, K. Canna, and C. S. McArdle, "Systemic inflammatory response predicts survival following curative resection of colorectal cancer," British Journal of Surgery, vol. 90, no. 2, pp. 215-219, 2003.

[335] C. Miki, N. Konishi, E. Ojima, T. Hatada, Y. Inoue, and M. Kusunoki, "C-reactive protein as a prognostic variable that reflects uncontrolled up-regulation of the IL-1-IL-6 network system in colorectal carcinoma," Digestive Diseases and Sciences, vol. 49, no. 6, pp. 970-976, 2004.

[336] J. E. M. Crozier, R. F. McKee, C. S. McArdle et al., "The presence of a systemic inflammatory response predicts poorer survival in patients receiving adjuvant 5-FU chemotherapy following potentially curative resection for colorectal cancer," British Journal of Cancer, vol. 94, no. 12, pp. 1833-1836, 2006.

[337] M. Ishizuka, H. Nagata, K. Takagi, T. Horie, and K. Kubota, "Inflammation-based prognostic score is a novel predictor of postoperative outcome in patients with colorectal cancer," Annals of Surgery, vol. 246, no. 6, pp. 1047-1051, 2007.

[338] J. E. M. Crozier and D. C. McMillan, "Authors' reply: Preoperative but not postoperative systemic inflammatory response correlates with survival in colorectal cancer," British Journal of Surgery, vol. 94, no. 11, pp. 1439-1440, 2007.

[339] M. Ishizuka, J. Kita, M. Shimoda et al., "Systemic inflammatory response predicts postoperative outcome in patients with liver metastases from colorectal cancer," Journal of Surgical Oncology, vol. 100, no. 1, pp. 38-42, 2009. 
[340] E. M. Siegel, C. M. Ulrich, E. M. Poole, R. S. Holmes, P. B. Jacobsen, and D. Shibata, "The effects of obesity and obesityrelated conditions on colorectal cancer prognosis," Cancer Control, vol. 17, no. 1, pp. 52-57, 2010.

[341] L. M. Forrest, D. C. McMillan, C. S. McArdle, W. J. Angerson, and D. J. Dunlop, "Evaluation of cumulative prognostic scores based on the systemic inflammatory response in patients with inoperable non-small-cell lung cancer," British Journal of Cancer, vol. 89, no. 6, pp. 1028-1030, 2003.

[342] A. M. Al Murri, J. M. S. Bartlett, P. A. Canney, J. C. Doughty, C. Wilson, and D. C. McMillan, "Evaluation of an inflammationbased prognostic score (GPS) in patients with metastatic breast cancer," British Journal of Cancer, vol. 94, no. 2, pp. 227-230, 2006.

[343] A. B. C. Crumley, D. C. McMillan, M. McKernan, A. C. McDonald, and R. C. Stuart, "Evaluation of an inflammationbased prognostic score in patients with inoperable gastrooesophageal cancer," British Journal of Cancer, vol. 94, no. 5, pp. 637-641, 2006.

[344] D. C. McMillan, J. E. M. Crozier, K. Canna, W. J. Angerson, and C. S. McArdle, "Evaluation of an inflammation-based prognostic score (GPS) in patients undergoing resection for colon and rectal cancer," International Journal of Colorectal Disease, vol. 22, no. 8, pp. 881-886, 2007.

[345] E. F. Leitch, M. Chakrabarti, J. E. M. Crozier et al., "Comparison of the prognostic value of selected markers of the systemic inflammatory response in patients with colorectal cancer," British Journal of Cancer, vol. 97, no. 9, pp. 1266-1270, 2007.

[346] A. T. Chan, S. Ogino, and C. S. Fuchs, "Aspirin use and survival after diagnosis of colorectal cancer," Journal of the American Medical Association, vol. 302, no. 6, pp. 649-658, 2009.

[347] F. Osorio-Costa, G. Z. Rocha, M. M. Dias, and J. B. Carvalheira, "Epidemiological and molecular mechanisms aspects linking obesity and cancer," Arquivos Brasileiros de Endocrinologia \& Metabologia, vol. 53, no. 2, pp. 213-226, 2009.

[348] R. C. Travis and T. J. Key, "Oestrogen exposure and breast cancer risk," Breast Cancer Research, vol. 5, no. 5, pp. 239-247, 2003.

[349] C. Schairer, D. Hill, S. R. Sturgeon et al., "Serum concentrations of IGF-I, IGFBP-3 and c-peptide and risk of hyperplasia and cancer of the breast in postmenopausal women," International Journal of Cancer, vol. 108, no. 5, pp. 773-779, 2004.

[350] P. Toniolo, P. F. Bruning, A. Akhmedkhanov, J. M. Bonfrer, K. L. Koenig, A. Lukanova et al., "Serum insulin-like growth factor-I and breast cancer," International Journal of Cancer, vol. 88, no. 5, pp. 828-832, 2000.

[351] R. Kaaks, P. Toniolo, A. Akhmedkhanov et al., "Serum Cpeptide, insulin-like growth factor (IGF)-I, IGF-binding proteins, and colorectal cancer risk in women," Journal of the National Cancer Institute, vol. 92, no. 19, pp. 1592-1600, 2000.

[352] G. Yang, G. Lu, F. Jin et al., "Population-based, case-control study of blood C-peptide level and breast cancer risk," Cancer Epidemiology Biomarkers and Prevention, vol. 10, no. 11, pp. 1207-1211, 2001.

[353] P. J. Goodwin, M. Ennis, K. I. Pritchard et al., "Insulin-like growth factor binding proteins 1 and 3 and breast cancer outcomes," Breast Cancer Research and Treatment, vol. 74, no. 1, pp. 65-76, 2002.

[354] L. Tessitore, B. Vizio, D. Pesola et al., "Adipocyte expression and circulating levels of leptin increase in both gynaecological and breast cancer patients," International Journal of Oncology, vol. 24, no. 6, pp. 1529-1535, 2004.
[355] A. Maccio and C. Madeddu, "Obesity, inflammation, and postmenopausal breast cancer: therapeutic implications," Scientific World Journal, vol. 11, pp. 2020-2036, 2011.

[356] N. Yin, D. Wang, H. Zhang et al., "Molecular mechanisms involved in the growth stimulation of breast cancer cells by leptin," Cancer Research, vol. 64, no. 16, pp. 5870-5875, 2004.

[357] W. Metzler, S. Fischer, C. Köhler, F. Pistrosch, B. Kindel, and M. Hanefeld, "Insulin resistance and metabolic parameters in type 2 diabetic patients," European Journal of Internal Medicine, vol. 13, no. 2, pp. 108-114, 2002.

[358] Y. Matsuzawa, "Adiponectin: identification, physiology and clinical relevance in metabolic and vascular disease," Atherosclerosis Supplements, vol. 6, no. 2, pp. 7-14, 2005.

[359] A. Schäffler, H. Herfarth, G. Paul et al., "Identification of influencing variables on adiponectin serum levels in diabetes mellitus type 1 and type 2," Experimental and Clinical Endocrinology and Diabetes, vol. 112, no. 7, pp. 383-389, 2004.

[360] E. Brakenhielm, N. Veitonm?ki, R. Cao, S. Kihara, Y. Matsuzawa et al., "Adiponectin-induced antiangiogenesis and antitumor activity involve caspase-mediated endothelial cell apoptosis," Proceedings of the National Academy of Sciences of the United States of America, vol. 101, no. 8, pp. 2476-2481, 2004.

[361] M. Pignatelli, C. Cocca, A. Santos, and A. Perez-Castillo, "Enhancement of BRCA1 gene expression by the peroxisome proliferator-activated receptor $\gamma$ in the MCF-7 breast cancer cell line," Oncogene, vol. 22, no. 35, pp. 5446-5450, 2003.

[362] A. Purohit, S. P. Newman, and M. J. Reed, "The role of cytokines in regulating estrogen synthesis: implications for the etiology of breast cancer," Breast Cancer Research, vol. 4, no. 2, pp. 65-69, 2002.

[363] M. L. Slattery, K. Curtin, C. Sweeney et al., "Modifying effects of IL-6 polymorphisms on body size-associated breast cancer risk," Obesity, vol. 16, no. 2, pp. 339-347, 2008.

[364] B. Dirat, L. Bochet, M. Dabek et al., "Cancer-associated adipocytes exhibit an activated phenotype and contribute to breast cancer invasion," Cancer Research, vol. 71, no. 7, pp. 24552465, 2011.

[365] B. L. Pierce, R. Ballard-Barbash, L. Bernstein et al., "Elevated biomarkers of inflammation are associated with reduced survival among breast cancer patients," Journal of Clinical Oncology, vol. 27, no. 21, pp. 3437-3444, 2009.

[366] A. Lukanova, E. Lundin, A. Micheli et al., "Circulating levels of sex steroid hormones and risk of endometrial cancer in postmenopausal women," International Journal of Cancer, vol. 108, no. 3, pp. 425-432, 2004.

[367] A. S. Greenberg and M. L. McDaniel, "Identifying the links between obesity, insulin resistance and $\beta$-cell function: potential role of adipocyte-derived cytokines in the pathogenesis of type 2 diabetes," European Journal of Clinical Investigation, vol. 32, no. 3, pp. 24-34, 2002.

[368] V. Chopra, T. V. Dinh, and E. V. Hannigan, "Serum levels of interleukins, growth factors and angiogenin in patients with endometrial cancer," Journal of Cancer Research and Clinical Oncology, vol. 123, no. 3, pp. 167-172, 1997.

[369] R. Punnonen, K. Teisala, T. Kuoppala, B. Bennett, and J. Punnonen, "Cytokine production profiles in the peritoneal fluids of patients with malignant or benign gynecologic tumors," Cancer, vol. 83, no. 4, pp. 788-796, 1998.

[370] S. Bellone, K. Watts, S. Cane' et al., "High serum levels of interleukin-6 in endometrial carcinoma are associated with uterine serous papillary histology, a highly aggressive and 
chemotherapy-resistant variant of endometrial cancer," Gynecologic Oncology, vol. 98, no. 1, pp. 92-98, 2005.

[371] M. Slater, M. Cooper, and C. R. Murphy, "Human growth hormone and interleukin- 6 are upregulated in endometriosis and endometrioid adenocarcinoma," Acta Histochemica, vol. 108, no. 1, pp. 13-18, 2006.

[372] L. Dossus, S. Rinaldi, S. Becker et al., "Obesity, inflammatory markers, and endometrial cancer risk: a prospective CaseControl Study," Endocrine-Related Cancer, vol. 17, no. 4, pp. 1007-1019, 2010.

[373] T. E. Vaskivuo, F. Stenbäck, and J. S. Tapanainen, "Apoptosis and apoptosis-related factors Bcl-2, Bax, tumor necrosis factor- $\alpha$, and NF- $\kappa$ B in human endometrial hyperplasia and carcinoma," Cancer, vol. 95, no. 7, pp. 1463-1471, 2002.

[374] J. Pallares, J. L. Martínez-Guitarte, X. Dolcet et al., "Abnormalities in the NF- $\kappa \mathrm{B}$ family and related proteins in endometrial carcinoma," Journal of Pathology, vol. 204, no. 5, pp. 569-577, 2004.

[375] A. Purohit and M. J. Reed, "Regulation of estrogen synthesis in postmenopausal women," Steroids, vol. 67, no. 12, pp. 979-983, 2002. 


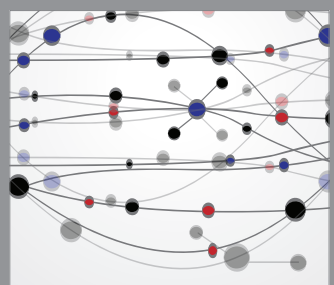

The Scientific World Journal
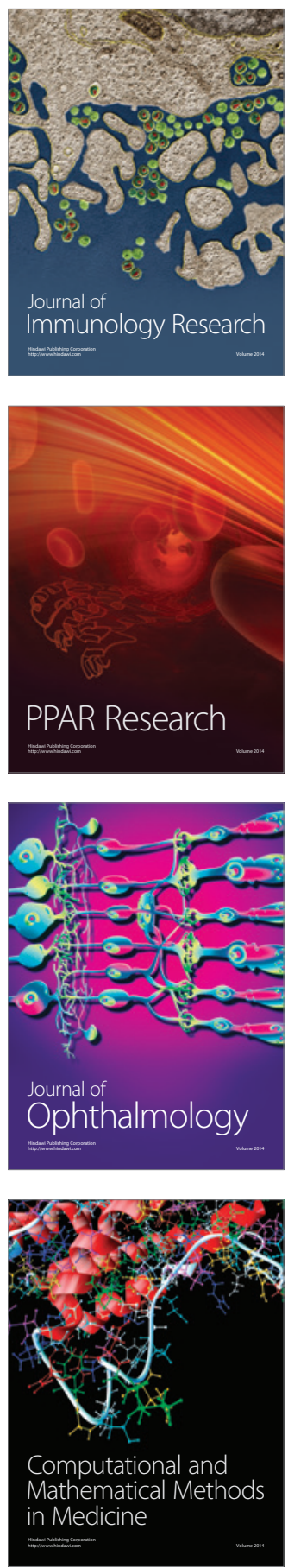

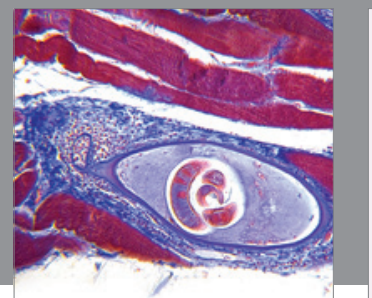

Gastroenterology

Research and Practice
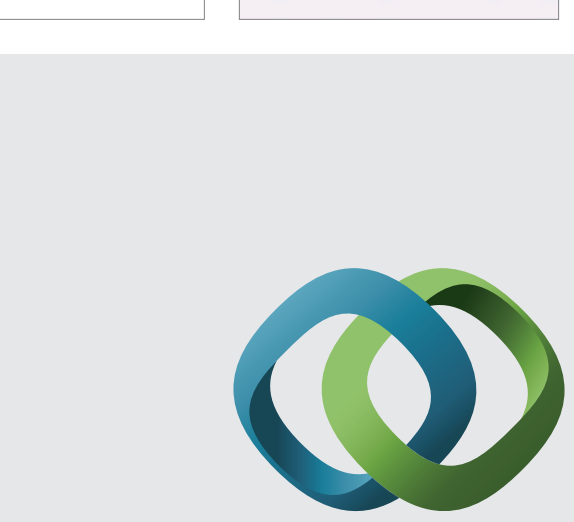

\section{Hindawi}

Submit your manuscripts at

http://www.hindawi.com
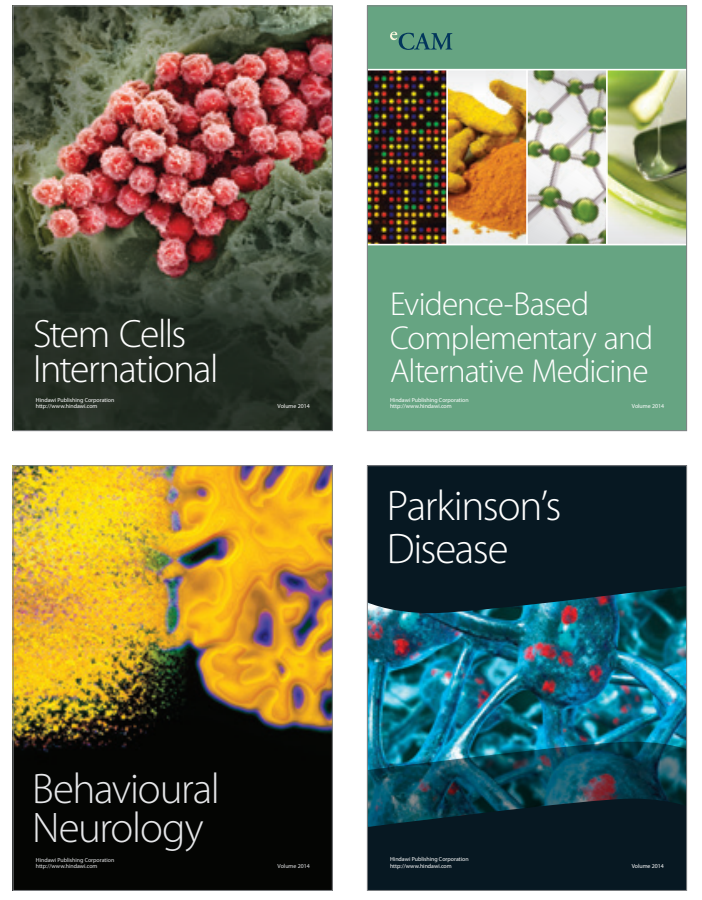
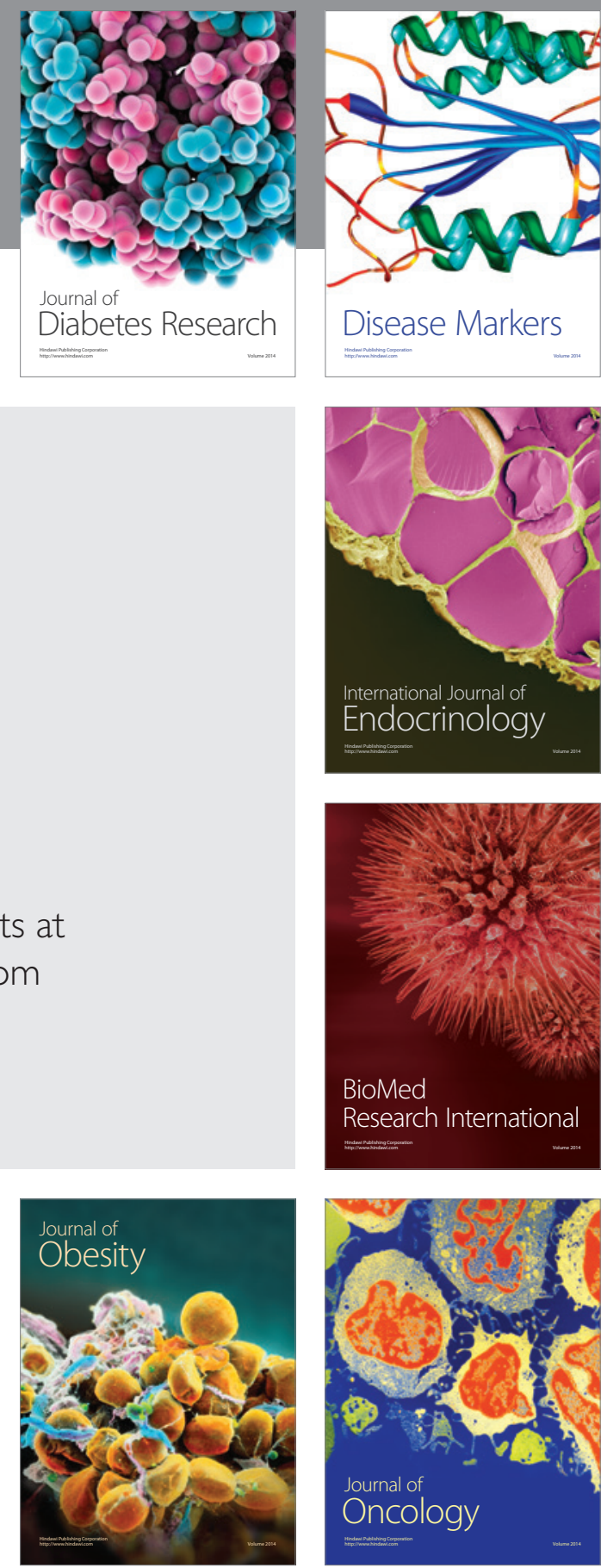

Disease Markers
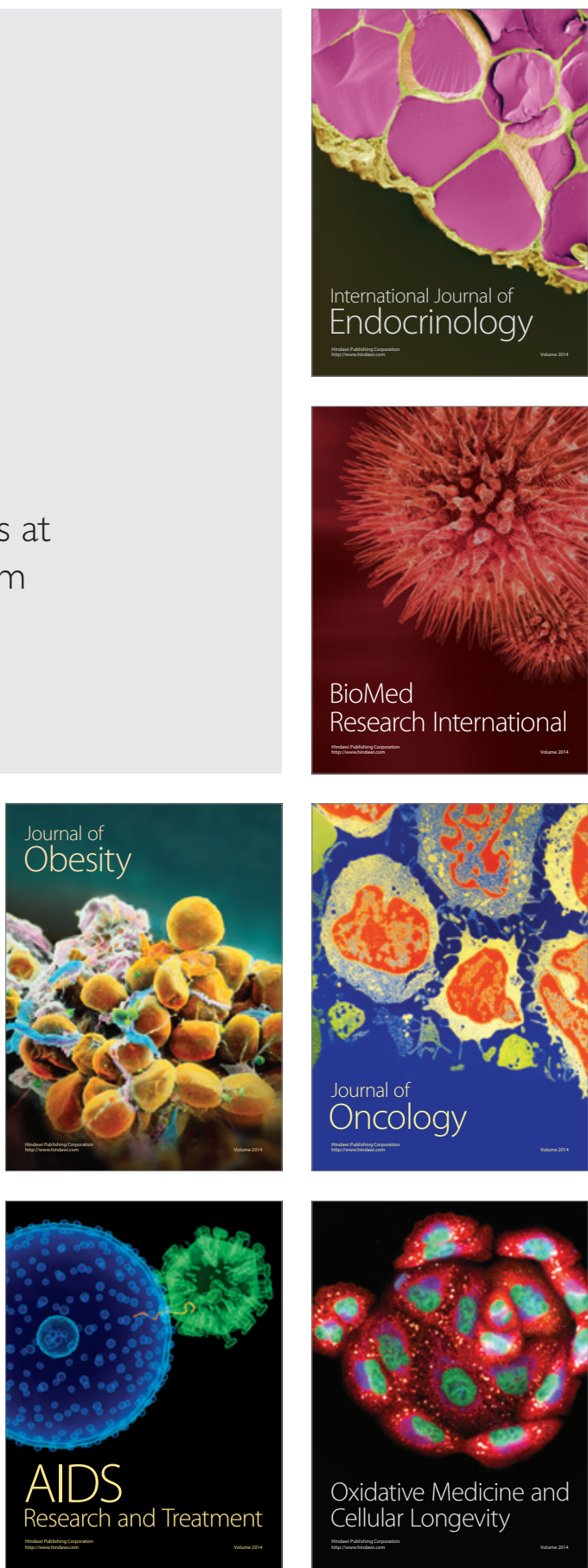